ARTICLE

https://doi.org/10.1038/s41467-019-13928-2

\title{
Structure-guided design of pure orthosteric inhibitors of $\alpha$ llb $\beta 3$ that prevent thrombosis but preserve hemostasis
}

\author{
Brian D. Adair 1,2,3, José L. Alonso 1,2,3, Johannes van Agthoven1,2,3, Vincent Hayes ${ }^{4}$, Hyun Sook Ahn ${ }^{4}$,
} I-Shing Yu (i) ${ }^{5}$, Shu-Wha Lin ${ }^{6}$, Jian-Ping Xiong ${ }^{1,2,3}$, Mortimer Poncz ${ }^{4} \&$ M. Amin Arnaout (i) ${ }^{1,2,3 \star}$

A prevailing dogma is that inhibition of vascular thrombosis by antagonizing platelet integrin $\alpha$ llb $\beta 3$ cannot be achieved without compromising hemostasis, thus causing serious bleeding and increased morbidity and mortality. It is speculated that these adverse outcomes result from drug-induced activating conformational changes in $\alpha$ llb $\beta 3$ but direct proof is lacking. Here, we report the structure-guided design of peptide $\mathrm{Hr} 10$ and a modified form of the partial agonist drug tirofiban that act as "pure" antagonists of $\alpha$ llb $\beta 3$, i.e., they no longer induce the conformational changes in $\alpha \mathrm{llb} \beta 3$. Both agents inhibit human platelet aggregation but preserve clot retraction. Hr10 and modified tirofiban are as effective as partial agonist drugs in inhibiting vascular thrombosis in humanized mice, but neither causes serious bleeding, establishing a causal link between partial agonism and impaired hemostasis. Pure orthosteric inhibitors of $\alpha \mathrm{llb} \beta 3$ may thus provide safer alternatives for human therapy, and valuable tools to probe structure-activity relationships in integrins.

\footnotetext{
${ }^{1}$ Leukocyte Biology \& Inflammation Program, and Structural Biology Program, Massachusetts General Hospital, Boston, MA 02114, USA. ${ }^{2}$ Division of Nephrology, Department of Medicine, Massachusetts General Hospital, Boston, MA 02114, USA. ${ }^{3}$ Harvard Medical School, Boston, MA 02115, USA. ${ }^{4}$ Division of Hematology, The Childrens Hospital of Philadelphia, Philadelphia, PA 19104, USA. ${ }^{5}$ Laboratory Animal Center, College of Medicine, National Taiwan University, Taipei, Taiwan. ${ }^{6}$ Department of Clinical Laboratory Sciences and Medical Biotechnology, National Taiwan University, Taipei, Taiwan. *email: aarnaout1@mgh.harvard.edu
} 
$\mathrm{P}$ latelet activation and accumulation at the site of blood vessel injury are the initial steps in hemostasis. When activated by several agonists, including adenosine diphosphate (ADP), thrombin, or collagen, platelets adhere to the disrupted surface, and aggregate upon binding of soluble fibrinogen (FB) or other proteins ${ }^{1}$ to agonist-activated $\alpha \operatorname{IIb} \beta 3^{2}$. Fibrin generated by thrombin at or near the platelet surface also binds aIIb $\beta 3$, driving clot retraction ${ }^{3}$, thereby consolidating the integrity of the hemostatic plug, restoring blood flow, and promoting wound closure ${ }^{4}$. Excessive platelet activation by agonists may lead to the formation of occlusive thrombi, which are responsible for acute myocardial infarction and stroke $\mathrm{e}^{5}$, hemodialysis access failure $^{6}$, early loss of kidney allograft ${ }^{7}$ and tumor growth, and metastasis ${ }^{8}$.

The three parenteral anti- $\alpha \mathrm{IIb} \beta 3$ drugs eptifibatide, tirofiban, and abciximab have demonstrated efficacy in reducing death and ischemic complications in victims of heart attacks 9 . However, their clinical use in acute coronary syndrome has been associated with serious bleeding, which often requires cessation of therapy, putting heart attack victims at high risk of rethrombosis. And oral anti- $\alpha$ IIb $\beta 3$ agents given to patients at risk of acute coronary syndrome were abandoned because of the increased risk of patient death linked to paradoxical coronary thrombosis ${ }^{10,11}$. Concluding that the adverse outcomes resulting from targeting $\alpha \mathrm{IIb} \beta 3$ are unavoidable, pharmaceutical companies developed inhibitors of the platelet $\mathrm{ADP}$ receptor $\mathrm{P}_{2} \mathrm{Y}_{12}$ and the thrombin receptor PAR1, both acting upstream of $\alpha \mathrm{IIb} \beta 3$. However, a considerable number of patients receiving these newer drugs continue to experience serious bleeding and thrombotic events ${ }^{12}$. Thus, there remains an unmet clinical need for new antithrombosis drugs that maintain efficacy while preserving hemostasis ${ }^{13}$.

Previous studies have shown that the three current anti- $\alpha \mathrm{IIb} \beta 3$ drugs are partial agonists, i.e., they trigger large activating conformational changes in $\alpha \operatorname{IIb} \beta 3$ that enhance receptor binding to physiologic ligand, promoting thrombosis ${ }^{14}$. These drugs also induce neoepitopes for natural antibodies, causing immune thrombocytopenia ${ }^{15}$. X-ray structures of unliganded and ligandbound integrins ${ }^{16-18}$ showed that the conformational changes in the integrin induced by binding of ligands or ligand-mimetic drugs are initiated in the integrin ligand-binding vWFA domain (A- or I domain). Ligand binding to $\beta 3$ integrins triggers tertiary changes in the A domain of the $\beta 3$ subunit ( $\beta$ A domain), comprising the inward movement of the N-terminal $\alpha 1$ helix (reported by movement of $\beta \mathrm{A}-\mathrm{Y}^{122}$ ) toward the $\mathrm{Mg}^{2+}$ or $\mathrm{Mn}^{2+}$ ion coordinated at the metal ion-dependent adhesion site (MIDAS). This reshapes the C-terminal F-a7 loop and repositions the $a 7$ helix causing a swing-out of the hybrid domain underneath the $\beta \mathrm{A}$ domain, which converts the integrin from the genu-bent to the genu-extended conformation, separates the transmembrane and cytoplasmic tails, allowing formation of the integrin-cytoskeleton interactions that mediate dynamic cell adhesion 19

Recently, we have shown that the above conformational changes in integrin $\alpha \mathrm{V} \beta 3$ can be prevented by binding of the $\alpha V \beta 3$-specific peptide hFN10, a modified high-affinity mutant peptide derived from the 10th type III domain of fibronectin $(\mathrm{FN} 10)^{20}$. We traced this unexpected effect of a ligand to a stable, key $\pi-\pi$ stacking interaction between the indole derivative, $\mathrm{W}^{1496}$, that immediately follows the RGD motif of hFN10, and the $\beta 3-Y^{122}$ in the ligand binding $\beta \mathrm{A}$ domain of $\alpha \mathrm{V} \beta 3^{20}$, a conclusion supported in a subsequent molecular dynamics study ${ }^{21}$. In this study, we evaluate the applicability of building such $\pi$ interactions for generation of pure orthosteric antagonists of other integrins, such as $\alpha \mathrm{IIb} \beta 3$. Accordingly, we have engineered a peptide and a small molecule targeting $\alpha \mathrm{IIb} \beta 3$ that are effective in preventing vascular thrombosis while preserving hemostasis, thus establishing a causal link between partial agonism and adverse outcomes, paving the way for potentially safer integrintargeted medical therapies.

\section{Results}

Development of peptide Hr10. Superimposing the $\beta \mathrm{A}$ domains from the crystal structures of $\alpha \operatorname{IIb} \beta 3 /$ eptifibatide complex (2vdn. $\mathrm{pdb})^{18}$ and $\alpha \mathrm{V} \beta 3 / \mathrm{hFN} 10$ (4mmz.pdb; Fig. 1a) revealed a potential clash between hFN10 and aIIb propeller, involving $S^{1500} \mathrm{~K}$ in the C-terminal F-G loop of hFN10 and $\mathrm{V}^{156} \mathrm{E}$ in the longer helixcontaining D2-A3 loop of aIIb. In addition, the short ligand

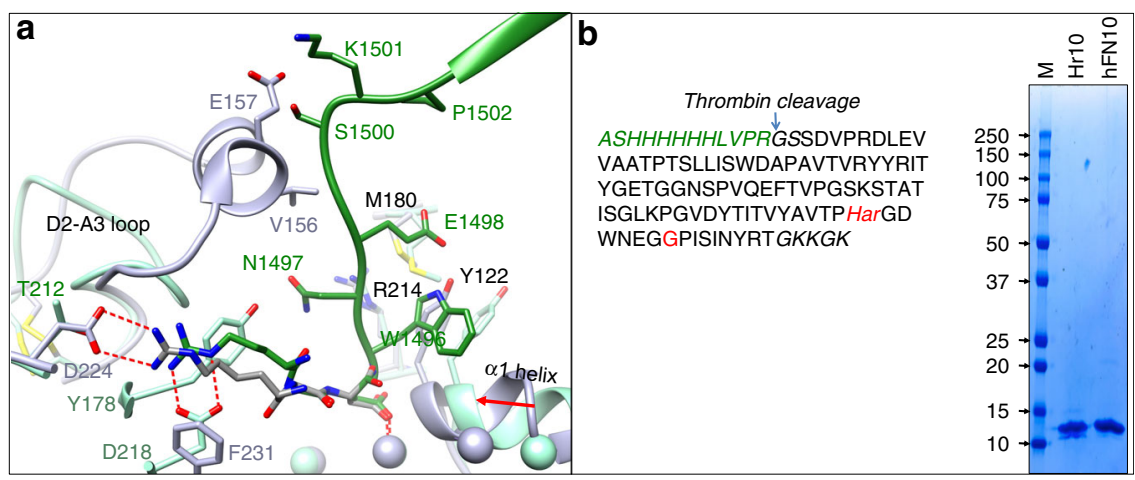

Fig. 1 Structure-guided design and binding properties of Hr10. a Ribbon diagrams of the crystal structures of $\alpha \vee \beta 3 / \mathrm{hFN} 10$ (light green, $4 \mathrm{mmz}$.pdb) and $\alpha$ llb $\beta 3$ /eptifibatide (light purple, 2vdn.pdb) superposed on the respective $\beta A$ domains, with the metal ions at the ligand-associated metal-binding site (LIMBS), MIDAS, and adjacent to MIDAS (ADMIDAS) shown as spheres in the respective colors. Relevant segments of the propeller and $\beta A$ domains and of hFN10 (dark green) and eptifibatide (dark gray) are shown. The MIDAS ion is ligated by the aspartate residue from each ligand. Residues (single letter code) specific to each structure are shown in the respective color, with residues or loops common in both shown in black. Oxygen, nitrogen, and sulfur atoms are in red, blue, and yellow, respectively. The inward movement (red arrow) of the $\alpha 1$ helix and ADMIDAS ion in $\alpha$ llb $\beta 3$, driven by binding of the partial agonist eptifibatide, is absent in $h F N 10$-bound $\alpha \mathrm{V} \beta 3$, the result of a $\pi-\pi$ interaction between $h F N 10-W^{1496}$ and $\beta A-Y^{122}$. $\beta A-R^{214}$ and $\beta A-M^{180}$ contribute to the stability of hFN10-W ${ }^{1496}$. Eptifibatide-Har ${ }^{2}$ forms a bidentate salt bridge with $\alpha$ llb-D 224 , whereas hFN10-R ${ }^{1493}$ contacts $\alpha V^{2}-D^{218}$ (replaced by $\mathrm{F}^{231}$ in $\alpha \mathrm{llb}$ ). b The translated sequence of His-tagged $\mathrm{Hr} 10$ lacking the $\mathrm{N}$-terminal methionine. Har and glycine substitutions are indicated in red. Alien residues are in italics (green text). The isotopically averaged calculated molecular weight of Hr10 was 11,969.3 (protein calculator v3.4 http:// protcalc.sourceforge.net/cgi-bin/protcalc). Inset, Coomassie stain of a whole 10-20\% SDS-PAGE showing purified Hr10 and hFN10 (8 $\mu$ in each lane). $\mathrm{MW}$ markers (in $\mathrm{kDa}$ ) are indicated. 

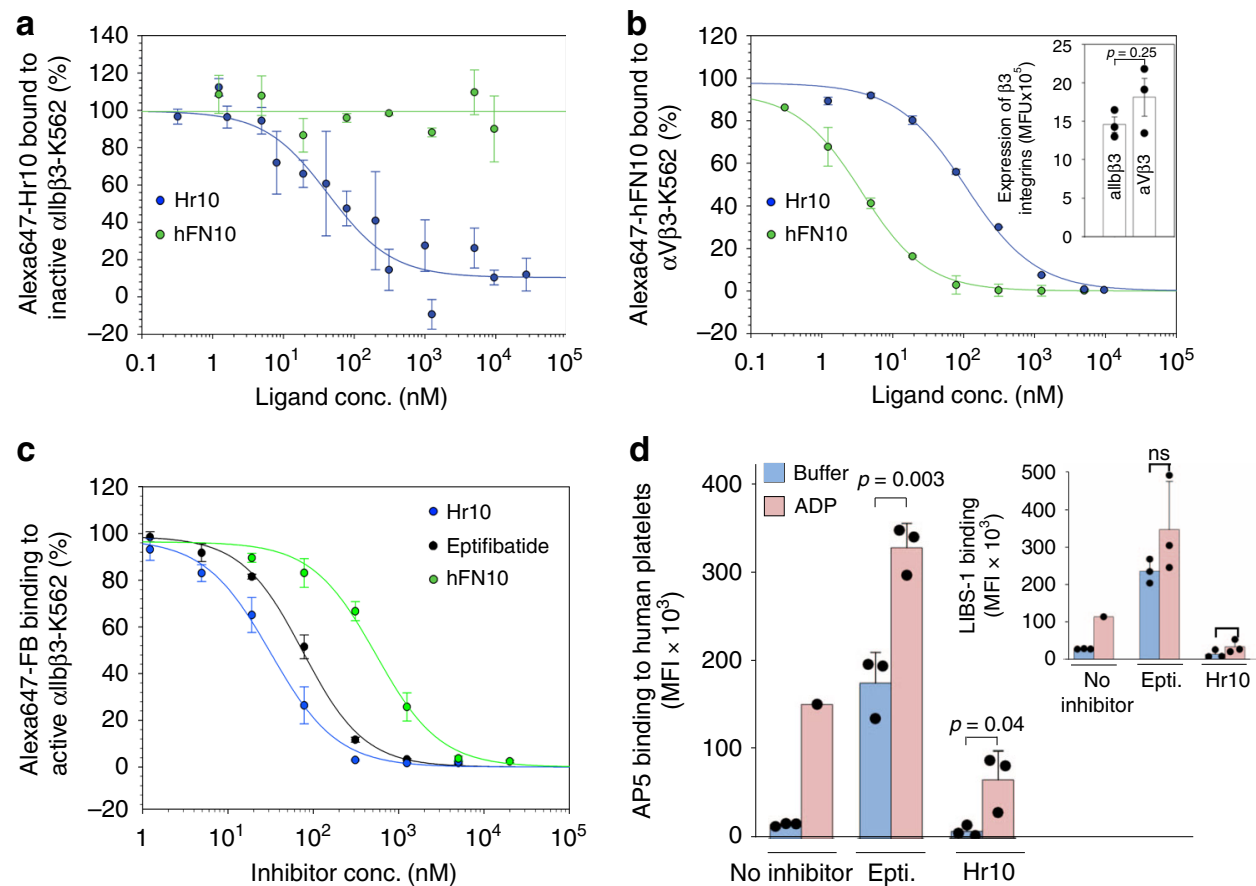

Fig. 2 Binding properties of Hr10. a Dose-response curves comparing displacement of Alexa647-labeled Hr10 from inactive $\alpha$ llb $\beta 3-K 562$ cells by unlabeled $\mathrm{Hr} 10$ ( $n=5,9$ replicates) or hFN10 $(n=3)$ analyzed by fluorescence-activated cell sorting (FACS). The mean fluorescence intensity (MFI) values for individual experiments were initially fit with a binding curve to determine minimum and maximum MFI values to use in scaling the data. The blue and green lines in a-c are a least-squares fit to the averages. The points and error bars indicate the mean and standard error for the scaled data. b Dose-response curves comparing displacement of Alexa647-labeled hFN10 binding to $\alpha \mathrm{V} \beta 3-\mathrm{K} 562$ cells by unlabeled hFN10 or Hr10. Data were generated as in $\mathbf{a}$. Inset, histograms (mean $+/-$ s.d., $n=3$ independent experiments) showing stable expression of the respective recombinant $\beta 3$ integrin on K562 cells as determined by binding of the $\beta 3$-specific mAb VI-PL2. Indicated $p$ value is determined by Student's t-test, two-tailed. c Dose-response curves (mean $+/$ - s.d., $n=3$ independent experiments) generated from FACS analysis showing displacement of Alexa- 647 labeled fibrinogen (FB) bound to activated $\alpha \mathrm{llb} \beta 3-\mathrm{K} 562$ in the presence of increasing concentrations of unlabeled Hr10, eptifibatide, or hFN10. The MFI values from the three separate FACS analyses were normalized individually before averaging as described in the methods. The $\mathrm{IC}_{50}$ values are stated in the text. Binding affinity of Hr10 to $\alpha$ llb $\beta 3$ was significantly higher than that of eptifibatide $\left(p=1.8 \times 10^{-5}\right.$, F-test, two-tailed). $\mathbf{d}$ Histograms (mean $+\mathrm{s} . \mathrm{d} ., n=3$ independent experiments) showing effect of $\mathrm{Hr} 10$ vs. eptifibatide (each at $1.5 \mu \mathrm{M}$ ) on integrin conformational changes. Binding of the activation-sensitive mAb AP5 or the extensionsensitive mAb LIBS-1 (inset) to human platelets in the absence or presence of ADP ( $5 \mu \mathrm{M})$ was assessed following flow cytometry. Binding of the two conformation-sensitive mAbs to ADP-activated platelets in the absence of the inhibitors was often complicated by platelet aggregation, thus only single measurements could be obtained for each $\mathrm{mAb}$ in this case. Indicated $p$ values were determined by Student's t-test, two-tailed; ns, not significant.

$\mathrm{R}^{1493}$ of hFN10 cannot make the critical bidentate salt bridge with aIIb- ${ }^{224}$. These feature account for the known inability of hFN10 to bind $a \operatorname{IIb} \beta 3^{22}$. We therefore substituted $S^{1500} \mathrm{~K}$ in hFN10 with glycine and replaced the ligand $\mathrm{R}^{1493}$ with the longer L-homoarginine (Har; Fig. 1b), changes that we predicted would not adversely affect FN10 folding or the $\pi-\pi$ stacking interaction between $\beta A-Y^{122}$ and $W^{1496}$ of the new peptide Hr10. The presence of Har in purified Hr10 (Fig. 1b, inset) was initially confirmed by mass spectroscopy (Supplementary Fig. 1).

Hr10 is an RGD-based pure antagonist of $\boldsymbol{\alpha I I b} \beta 3$. We measured binding of fluorescently labeled $\mathrm{Hr} 10$ and hFN10 to inactive recombinant $\alpha \mathrm{IIb} \beta 3$ and to $\alpha \mathrm{V} \beta 3$, each stably expressed in equivalent amounts on K562 cells (Fig. 2a, b; Supplementary Fig. 2). Hr10 bound $\alpha \operatorname{IIb} \beta 3$ with high affinity $\left(\mathrm{IC}_{50}=58.8+/-\right.$ $24.1 \mathrm{nM}$; mean \pm s.e.), with hFN10 showing no measurable binding to inactive $\alpha \operatorname{IIb} \beta 3$ (Fig. 2a). Hr10 continued to bind $\alpha \mathrm{V} \beta 3-\mathrm{K} 562$ but with much lower affinity when compared to hFN10 (IC 50 s of $107.9+/-23.1 \mathrm{nM}$ and $3.6+/-0.72 \mathrm{nM}$, respectively; Fig. 2b). Hr10 inhibited binding of Alexa647-labeled soluble $\mathrm{FB}$ to preactivated $\alpha \mathrm{IIb} \beta 3$ with high affinity $\left(\mathrm{IC}_{50} 30.3 \pm\right.$ $4.8 \mathrm{nM}$, mean \pm s.e.) that was $\sim 2.5$-fold higher than that of eptifibatide $\left(73.2 \pm 7.0 \mathrm{nM}, p=1.79 \times 10^{-5}, F\right.$-test, two-tailed; Fig. 2c). hFN10 bound minimally to preactivated $\alpha \mathrm{IIb} \beta 3-\mathrm{K} 562$, with an order of magnitude higher $\mathrm{IC}_{50}$ of $474.0 \pm 73.4 \mathrm{nM}$ (Fig. 2c).

Binding of eptifibatide at a clinically effective dose of $1.5 \mu \mathrm{M}^{23}$ to human platelets induced conformational changes in $\alpha \operatorname{IIb} \beta 3$ reported by binding of the activation-sensitive and extensionsensitive mAbs AP5 and LIBS-1, respectively ${ }^{20}$ (Fig. 2d). These changes were markedly enhanced in presence of $5 \mu \mathrm{M}$ ADP. In contrast, binding of $\mathrm{Hr} 10$ at $1.5 \mu \mathrm{M}$ did not induce these changes directly, and also suppressed binding of AP5 and LIBS-1 to ADPactivated platelets (Fig. 2d). Thus Hr10 acts as a pure orthosteric antagonist of $\alpha \mathrm{IIb} \beta 3$.

Crystal structure of $\boldsymbol{\alpha V} \boldsymbol{\beta} 3 / \mathrm{Hr} 10$ complex. To elucidate the structural basis of pure antagonism, we determined the crystal structure of $\alpha \mathrm{V} \beta 3 / \mathrm{Hr} 10$ complex at $3.1 \AA$ resolution (Fig. 3a and Supplementary Table 1) by soaking $\mathrm{Hr} 10$ into preformed aV $\beta 3$ ectodomain crystals (crystal packing of the aIIb $\beta 3$ ectodomain does not allow access of large ligands such as Hr10 to the MIDAS). Hr10-Har ${ }^{1493}$ forms a bidentate salt bridge with $\alpha \mathrm{V}-\mathrm{D}^{218}$ and a cation- $\pi$ interaction with $\alpha \mathrm{V}-\mathrm{Y}^{178}$ but does not contact $a \mathrm{~V}-\mathrm{Th}^{212}$ (which replaces aIIb-D ${ }^{224}$ ). Hr10-D ${ }^{1495}$ directly coordinates the metal ion at MIDAS, with Hr10-W 1496 making a $\pi-\pi$ stacking interaction with $\beta A-Y^{122}$, stabilized by an Hr10-W ${ }^{1496} \mathrm{~S}-\pi$ interaction with $\beta \mathrm{A}-\mathrm{M}^{180}$ (Fig. 3a), and by a 

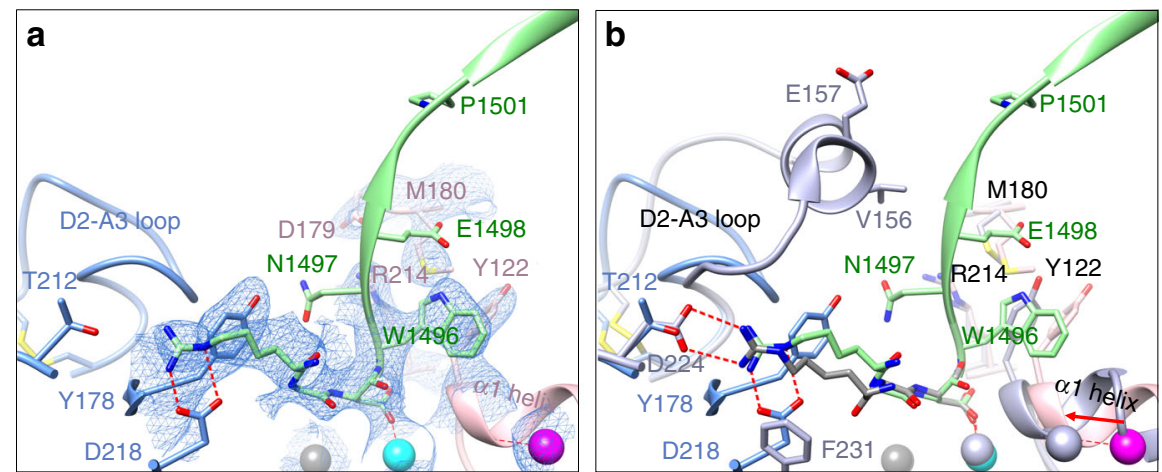

Fig. 3 Crystal structure of $\boldsymbol{\alpha} \mathbf{V} \boldsymbol{\beta} \mathbf{3} / \mathbf{H r 1 0}$ complex. a Ribbon diagram of the crystal structure of $\alpha \mathrm{V} \beta 3$-bound Hr10 (same view as Fig. 1a) showing 2 fo-fc map at $1.0 \sigma$ (blue mesh) of the ligand-binding region. Relevant portions of $\mathrm{Hr} 10$ (light green), $\alpha \mathrm{V}$ propeller (light blue), and the $\beta A$ domain of $\beta 3$ subunit (rose color) are shown. Side chains of amino acids (single letter code) are shown as sticks in the respective colors. The Mn ${ }^{2+}$ ions at LIMBS, MIDAS, and ADMIDAS are in grey, cyan, and magenta spheres, respectively. Oxygen, nitrogen, and sulfur atoms are colored as in Fig. 1a. Water molecules are not shown. Hr10's W ${ }^{1496}$ forms a $\pi-\pi$ interaction with $\beta A-Y^{122}$, and Hr10-Har ${ }^{1493}$ forms a bidentate salt bridge with $\alpha \mathrm{V}-\mathrm{D}^{218}$. b Ribbon diagrams of the crystal structures of $\mathrm{Hr} 10 / \alpha \mathrm{V} \beta 3$ (light green) and eptifibatide/ $\alpha$ llb $\beta 3$ (light purple, 2vdn.pdb) superposed on the $\beta A$ domain of each. View, domain, side chain, and metal ion colors are as in $\mathbf{a}$. Note the removal of the predicted clash of $\mathrm{Hr} 10$ with D2-A3 loop of $\alpha$ llb and predicted formation of Hr10-Har ${ }^{1493} / \alpha$ llb-D $^{224}$ salt bridge.

hydrogen bond between the carbonyl oxygen of $\mathrm{W}^{1496}$ and $\mathrm{Ne}$ of $\beta \mathrm{A}-\mathrm{R}^{214}$. Bound Hr10 prevented the activating inward movement of the $\alpha 1$ helix (reported by $\beta 3-Y^{122}$ ) toward MIDAS, and the conformational changes at the $\mathrm{C}$-terminal end of the $\beta \mathrm{A}$ domain that normally initiate integrin extension. Superposition of the $\beta \mathrm{A}$ domains from the $\alpha \mathrm{V} \beta 3 / \mathrm{Hr} 10$ and $\alpha \mathrm{IIb} \beta 3 /$ eptifibatide structures (Fig. 3b) shows that the $S^{1500} \mathrm{~K} / \mathrm{G}$ substitution removes the predicted clash with the aIIb propeller. The $\mathrm{N} \varepsilon, \mathrm{Nh} 1$, and $\mathrm{Nh} 2$ amino groups of $\mathrm{Hr} 10-\mathrm{Har}^{1493}$ superpose well on those of eptifibatide-Har ${ }^{2}$ and could likewise form the critical bidentate salt bridge with $\alpha \mathrm{IIb}-\mathrm{D}^{224}$, accounting for the observed highaffinity binding of $\mathrm{Hr} 10$ to $\alpha \mathrm{IIb} \beta 3$. $\beta \mathrm{A}-\mathrm{Y}^{122}$ is replaced with Phe ${ }^{122}$ in mouse $\beta 3$, and the stabilizing salt bridge $\beta A-R^{214}$ makes with $\beta A-D^{179}$ (Fig. 3a) is replaced with a H-bond with $\beta A-N^{179}$ in mouse, both substitutions likely contributing to the weak binding of $\mathrm{Hr} 10$ to mouse $\alpha \mathrm{IIb} \beta 3$.

Effects of Hr10 on platelet aggregation and secretion. Hr10 was as effective as eptifibatide in blocking collagen-induced platelet aggregation but was somewhat less effective in blocking ADP- or TRAP-induced aggregation (Fig. 4a-d). The adenine nucleotides ADP and ATP are coreleased from dense $(\delta)$ - granules during platelet activation and interact with platelet $\mathrm{P}_{2}$ receptors to amplify ongoing platelet activation. Both $\mathrm{Hr} 10$ and eptifibatide (at $1.5 \mu \mathrm{M})$ significantly inhibited $\operatorname{ADP}(20 \mu \mathrm{M})$-induced ATP secretion from $\delta$ - granules (Fig. 4e), but did not significantly suppress ADP-induced release from a-granule (reported by CD62P surface expression) or lysosomes (reported by CD63 surface expression; Fig. 4f). This observation has been previously documented for $\alpha \operatorname{IIb} \beta 3$ antagonists ${ }^{24}$ and lead to the suggestion that ADP-induced a-granule release can occur independently of $\alpha \mathrm{IIb} \beta 3^{25}$.

Hr10 preserves thrombin-induced clot retraction. Clot retraction normally helps secure hemostasis in vivo as evidenced by increased bleeding in mice with impaired clot retraction ${ }^{26}$, or in recipients of any of the three anti- $\alpha \mathrm{IIb} \beta 3$ drugs ${ }^{4,27,28}$. We compared the effects of Hr10 and eptifibatide on thrombin-induced clot retraction in fresh human platelet-rich plasma (PRP) ${ }^{29}$. The kinetics of clot retraction were determined from quantification of serial images of the reaction acquired every $15 \mathrm{~min}$ for the 2-h duration of the assay. As shown in Fig. $5 \mathrm{a}, \mathrm{b}, \mathrm{Hr} 10$ (at $1.5 \mu \mathrm{M}$ ) did not inhibit clot retraction vs. buffer alone $(p=0.125, F$-test, two-tailed). In contrast, eptifibatide (at $1.5 \mu \mathrm{M}$ ) significantly blocked clot retraction vs. buffer $\left(p=4.5 \times 10^{-5}, F\right.$-test, twotailed), as previously shown ${ }^{27,30}$. aIIb $\beta 3$ antagonists that block platelet aggregation but not clot retraction have been reported to exhibit affinities to inactive $\alpha \mathrm{IIb} \beta 3$ that are $2-3$ logs lower than those to active $\alpha \operatorname{IIb} \beta 3^{3}$. This was not the case with $\operatorname{Hr} 10$, however: its binding affinities to inactive $\left(\mathrm{IC}_{50}=58.8+/-\right.$ $24.1 \mathrm{nM}$, nine determinations from five experiments) and active aIIb $\beta 3$ ( IC $_{50} 35.2+/-5.7 \mathrm{nM}, n=3$ experiments) were not significantly different ( $p=0.54, F$-test, two-tailed; Fig. $5 c)$, and were comparable to the affinity of eptifibatide to $\alpha \mathrm{IIb} \beta 3$ on resting platelets $\left(k_{\mathrm{D}}=120 \mathrm{nM}\right)^{31}$.

Effects of Hr10 in humanized mice. To evaluate the effects of the peptides Hr10 and eptifibatide on nascent thrombus formation under flow, we induced thrombin-mediated arteriolar injury in a humanized mouse model shown to predict clinical efficacy of anti-platelet agents ${ }^{32}$. NSG (NOD-scid-IL-2R $\gamma^{\text {null }}$ ) mice were made homozygous for human von Willebrand factor $\mathrm{R}^{1326 \mathrm{H}}$ $(\mathrm{vWF} R H / R H)^{32}$, a substitution that switches binding of vWF from mouse to human glycoprotein (GP) Ib/IX, accounting for the increased bleeding risk in these mice unless infused with human platelets. To assess the effects of $\mathrm{Hr} 10$ and eptifibatide on thrombus formation, each inhibitor was given to mice preinfused with human platelets (eptifibatide ${ }^{32}$, like $\mathrm{Hr} 10$, binds poorly to mouse $\alpha \mathrm{IIb} \beta 3$ ). Hr10 in equimolar concentrations to eptifibatide was as effective in preventing nascent occlusive thrombus formation at multiple sites of laser-induced arteriolar injury in the cremaster muscle (Fig. 6a). Hr10 did not cause significant human platelet clearance (Supplementary Fig. 3). Importantly, and in contrast to eptifibatide, Hr10 did not cause significant loss of blood in these mice (Fig. 6b).

Converting tirofiban into a pure $\alpha \mathrm{IIb} \beta 3$ antagonist. We next explored the feasibility of converting the $\alpha \operatorname{IIb} \beta 3$-specific nonpeptidic partial agonist drug tirofiban (molecular weight of 495.08; Fig. 7a, left panel) into a pure antagonist, guided by the present crystal structure of $\alpha \mathrm{V} \beta 3 / \mathrm{Hr} 10$ complex. Superposing the $\beta \mathrm{A}$ domains of $\alpha \mathrm{V} \beta 3 / \mathrm{Hr} 10$ and $\alpha \mathrm{IIb} \beta 3 /$ tirofiban (2vdm.pdb) structures show that the acidic moiety of each ligand and the following amide are nearly superimposable (r.m.s.d. $=0.9648$; Fig. 7b), suggesting that replacing the butane-sulfonamide moiety of tirofiban with an indole group could create the critical $\pi-\pi$ 


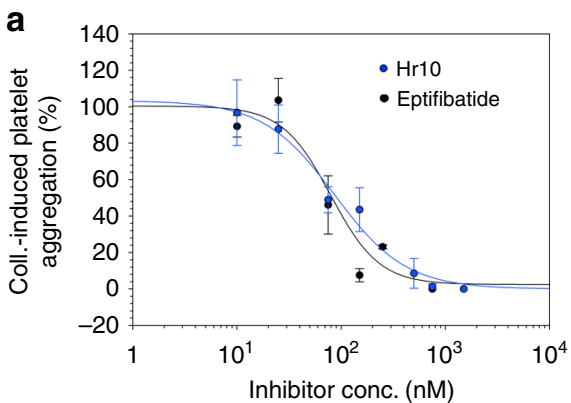

\begin{tabular}{|c|c|c|c|c|}
\hline Agonist & Inhibitor & $\begin{array}{c}\text { Mean IC } \\
(\mathrm{nM})\end{array}$ & S.E. & $\begin{array}{c}P \\
\text { value }\end{array}$ \\
\hline $\begin{array}{l}\text { Collagen } \\
(1 \mu \mathrm{g} / \mathrm{ml})\end{array}$ & $\begin{array}{l}\text { Hr10 } \\
\text { eptifibatide }\end{array}$ & $\begin{array}{l}75.5 \\
70.9 \\
\end{array}$ & \begin{tabular}{|l|}
23.3 \\
12.1 \\
\end{tabular} & 0.7 \\
\hline $\begin{array}{c}\text { ADP } \\
(20 \mu \mathrm{M})\end{array}$ & $\begin{array}{l}\text { Hr10 } \\
\text { eptifibatide }\end{array}$ & $\begin{array}{l}62.5 \\
26.3 \\
\end{array}$ & \begin{tabular}{|c|}
19.2 \\
2.8 \\
\end{tabular} & 0.0024 \\
\hline $\begin{array}{l}\text { TRAP } \\
(10 \mu \mathrm{M})\end{array}$ & $\begin{array}{l}\text { Hr10 } \\
\text { eptifibatide }\end{array}$ & $\begin{array}{l}51.0 \\
28.0\end{array}$ & \begin{tabular}{|c|}
12.3 \\
3.1
\end{tabular} & 0.023 \\
\hline
\end{tabular}
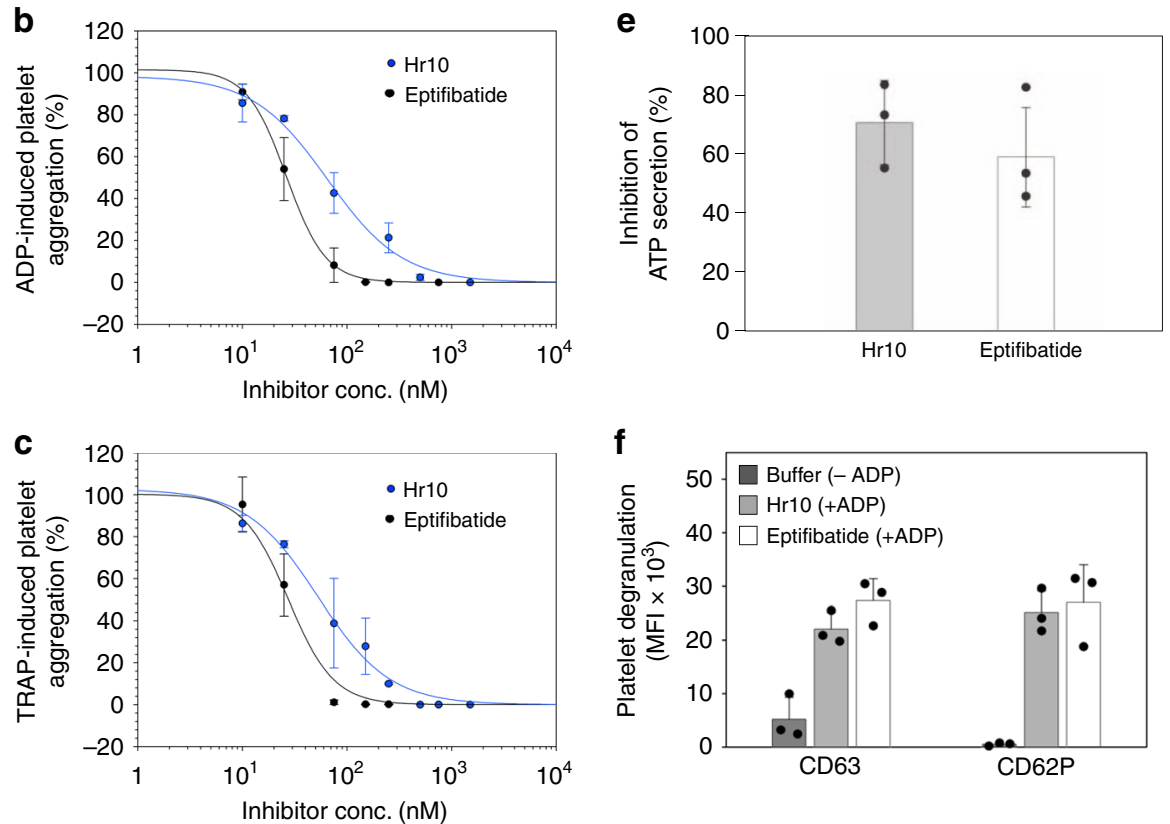

Fig. 4 Effect of Hr10 and eptifibatide on platelet aggregation and secretion. a-c Dose-response curves (mean $+/-$ s.e., $n=3$ experiments, each from a different donor) showing effects of the inhibitors on aggregation induced by collagen (Coll.) $(2 \mu \mathrm{g} / \mathrm{ml}) \mathbf{a}$, ADP ( $20 \mu \mathrm{M}) \mathbf{b}$, or TRAP (10 $\mu \mathrm{M}) \mathbf{c}$. Points for the integrated impedance from the three experiments were individually normalized prior to averaging and are displayed with least-squares fits to the mean values. The respective $\mathrm{IC}_{50}$, s.e., and $p$ values ( $F$-test, two-tailed) are listed in d. e-f Histograms (mean + or $+/-$ s.d., $n=3$ independent experiments) showing the effect of $\mathrm{Hr} 10$ and eptifibatide (each at $1.5 \mu \mathrm{M})$ on ADP $(20 \mu \mathrm{M})$-induced ATP secretion $(\mathbf{e}, p=0.41$, Student's $t$-test, two-tailed) and surface expression of CD63 and CD62P $\mathbf{f}$ on human platelets. No differences in expression of CD63 $(p=0.15)$ or CD62P $(p=0.72)$, both Student's $t$-test, twotailed, were found in platelets exposed to eptifibatide or Hr10. Buffer sample in $\mathbf{f}$ represents marker expression in the absence of ADP.

stacking interaction with $\beta A-Y^{122}$. We selected the indole derivative benzoxazole in order to stabilize this interaction further by formation of a hydrogen bond between the benzoxazole oxygen and $\mathrm{N \varepsilon}$ of $\beta \mathrm{A}-\mathrm{R}^{214}$ as in the $\alpha \mathrm{V} \beta 3 / \mathrm{Hr} 10$ structure. Structure of such modified tirofiban (M-tirofiban; Fig. 7a, right panel; Supplementary Fig. 4) in complex with inactive $\alpha \operatorname{IIb} \beta 3$ (3fcs.pdb) was then modeled in $\operatorname{Coot}^{33}$ by geometry minimization with a library generated by eLBOW in Phenix ${ }^{34}$. In this model (Fig. $7 \mathrm{~b}$ ), the RGD-like moiety of M-tirofiban superimposes nicely onto that of tirofiban, with the benzoxazole moiety forming a $\pi-\pi$ stacking interaction $(4.4 \AA)$ with $\beta \mathrm{A}-\mathrm{Y}^{122}$, and the benzoxazole oxygen forming a hydrogen bond (3.2 $\AA$ ) with $\mathrm{N \varepsilon}$ of $\beta \mathrm{A}-\mathrm{R}^{214}$, arrangements predicted to freeze $\alpha \mathrm{IIb} \beta 3$ in the inactive conformation.

In vitro and in vivo activities of M-tirofiban. The aIIb $\beta 3$ specific M-tirofiban (Supplementary Fig. 5) effectively blocked FB binding to preactivated $\alpha \operatorname{IIb} \beta 3$ (Fig. 7c), and prevented ADP-induced human platelet aggregation even better than eptifibatide (Fig.7d). The observed $\sim 10$-fold reduction in affinity of M-tirofiban vs. tirofiban to $\alpha \mathrm{IIb} \beta 3$ likely reflects weaker H-bonding of M-tirofiban's benzoxazole oxygen (vs. tirofiban's sulfonamide oxygen) with $\mathrm{Ne}$ of $\beta 3-\mathrm{R}^{214}$ and perhaps loss of hydrophobic contacts with the integrin by the deleted butane moiety.

In contrast to tirofiban (used at a clinically effective concentration of $0.15 \mu \mathrm{M}^{23}$ ), M-tirofiban (at the equipotent concentration of $1.5 \mu \mathrm{M})$ neither induced the activating conformational changes in $\alpha \operatorname{IIb} \beta 3$ directly nor when these changes were induced by ADP (Fig. 8a). It also preserved thrombininduced clot retraction vs. tirofiban (Fig. 8b), and exhibited equivalent binding affinities to active and inactive $\alpha \operatorname{IIb} \beta 3$ (Fig. $8 \mathrm{c}$, d). In vivo, M-tirofiban did not affect human platelet clearance (Supplementary Fig. 3), and was as effective as tirofiban and Hr10 in preventing redox-induced thrombosis following carotid artery injury (Fig. 9a). Significantly, like $\mathrm{Hr} 10$ and in contrast to tirofiban, M-tirofiban did not increase blood loss (Fig. 9b) or bleeding time (Fig. 9c) in mice.

\section{Discussion}

The Achilles heel of current anti-thrombosis drugs that directly target $\alpha \mathrm{IIb} \beta 3$ is serious bleeding, an adverse outcome that remains high with use of the newer inhibitors of $\mathrm{P}_{2} \mathrm{Y}_{12}$ and thrombin receptors ${ }^{35,36}$. Several attempts are being made to develop new anti-thrombosis drugs that maintain efficacy but 
a

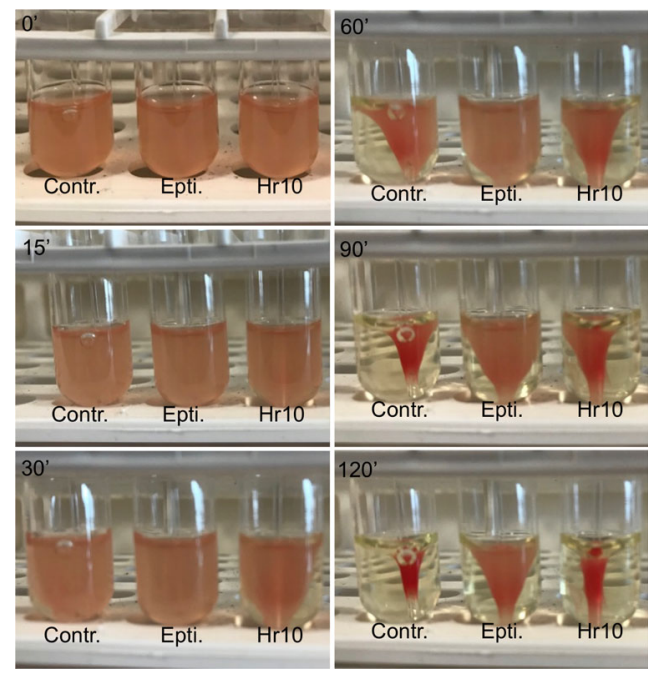

b

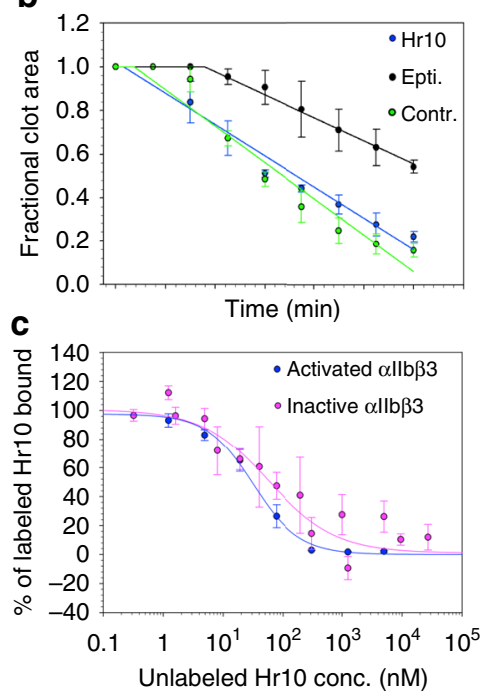

Fig. 5 Clot retraction and integrin binding studies. a Kinetics of clot retraction in the absence (Contr.) and presence of Hr10 or eptifibatide (Epti.) from a representative experiment, one of three conducted. Clot retraction took place around a central glass rod. A total of $5 \mu$ l of red blood cells were added per $1 \mathrm{ml}$ reaction to enhance color contrast for photography. Photographs shown were taken at timed intervals (in minutes) after addition of thrombin. $\mathbf{b}$ Time course (mean $+/-$ s.e.) from three clot retraction experiments, including the one shown in Fig. 5a. The plot shows the fractional area occupied by the clot at 15-min intervals with a linear regression through the points. No significant differences $(p=0.125$, F-test, two-tailed) were found in kinetics of clot retraction in buffer vs. Hr10. A lag period is noted with eptifibatide and clot retraction was significantly reduced vs. buffer $\left(p=4.5 \times 10^{-15}, F\right.$-test, twotailed). c Dose-response curves comparing displacement of Alexa488-labeled Hr10 binding to PT-25-activated $\alpha$ llb $\beta 3$ on K562 cells by increasing concentrations of unlabeled $\mathrm{Hr} 10$ with that to the inactive receptor (Fig. 2a). Cell binding was analyzed by FACS. The mean fluorescence intensity (MFI) values of binding to active $\alpha$ llb $\beta 3$ (mean $+/$ - s.e. of three independent experiments) were initially fit with a binding curve to determine minimum and maximum MFI values to use in scaling the data. The points and error bars indicate the mean and standard error for the scaled data. The red and black lines are a least-squares fit to the averages. No significant differences were found ( $p=0.54$, F-test, two-tailed).
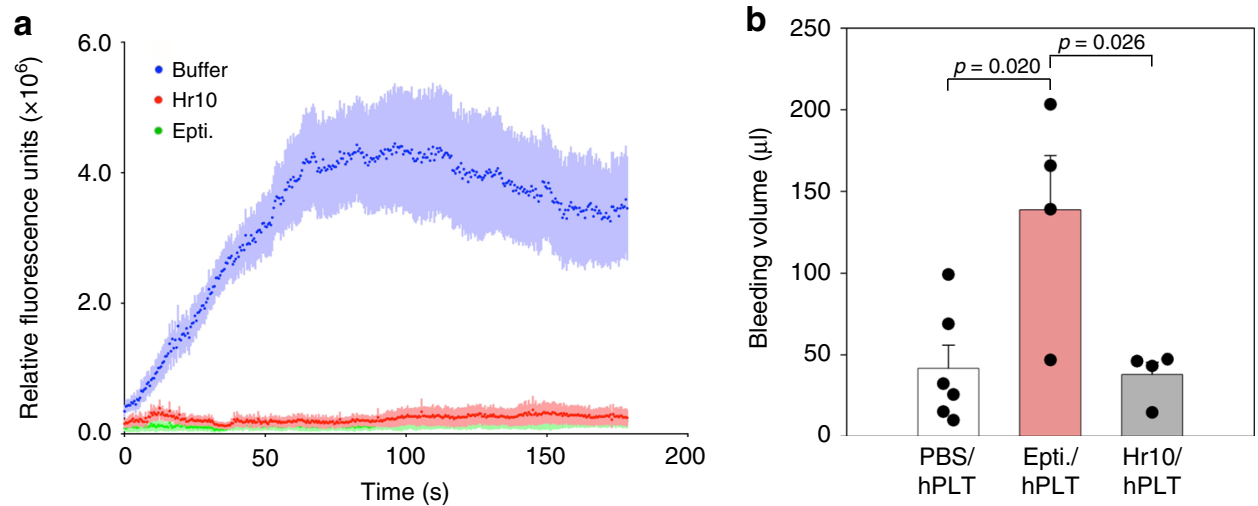

Fig. 6 Hr10 inhibits thrombosis without causing bleeding. a Graphs showing kinetics of human platelet accumulation at nascent laser-induced injury sites in cremaster muscle, 5 min following infusion of PBS or equimolar amounts of $\mathrm{Hr} 10$ or eptifibatide in the same buffer. Values represent the mean + s.e. of four mice per arm). There was no significant difference in human platelet accumulation in thrombi between Hr10- and eptifibatide-treated mice at each time point. $\mathbf{b}$ Histograms (mean + s.e.) showing baseline bleeding volume in $v W F R H / R H N S G$ mice infused with human platelets before (PBS; $n=6$ ) or after administration of eptifibatide (Epti; $n=4)$, or $\mathrm{Hr} 10(n=4)$. Epti. caused excessive loss of blood $(\sim 10 \%$ of blood volume of a normal mouse), which was absent in Hr10-treated mice. Difference between PBS- and Hr10-treated mice was not significant ( $p=0.94$, Student's $t$-test, two-tailed). The other $p$ values are shown.

preserve hemostasis. These include targeting collagen receptors a2 $\beta 1$ and GPVI ${ }^{37,38}$, accelerating ADP degradation with CD3939 or interfering with ADP-induced cell signaling with a $\mathrm{PI} 3 \mathrm{~K} \beta$ inhibitor $^{40}$. However, these approaches do not affect platelet activation induced by other potent agonists, and some targets (e.g., PI3K $\beta$ and $\alpha 2 \beta 1$ ) are not platelet specific. Platelet-leukocyte interactions are also being targeted: interfering with binding of leukocyte integrin CD11b to platelet GP1ba delayed thrombosis without prolonging bleeding time in normal mice ${ }^{41}$. However, platelet-leukocyte interactions are mediated by multiple receptor-counterreceptor pairs, the relative importance of which may vary with the nature of the pathologic state. Two recent attempts targeted $\alpha \mathrm{IIb} \beta 3$ more directly. In one approach, a short cytoplasmic $\beta 3$-derived peptide inhibited $\alpha \operatorname{IIb} \beta 3$ outside-in signaling and prevented thrombosis without prolonging bleeding time; however, it is not $\beta 3$-integrin specific ${ }^{30}$. The second 

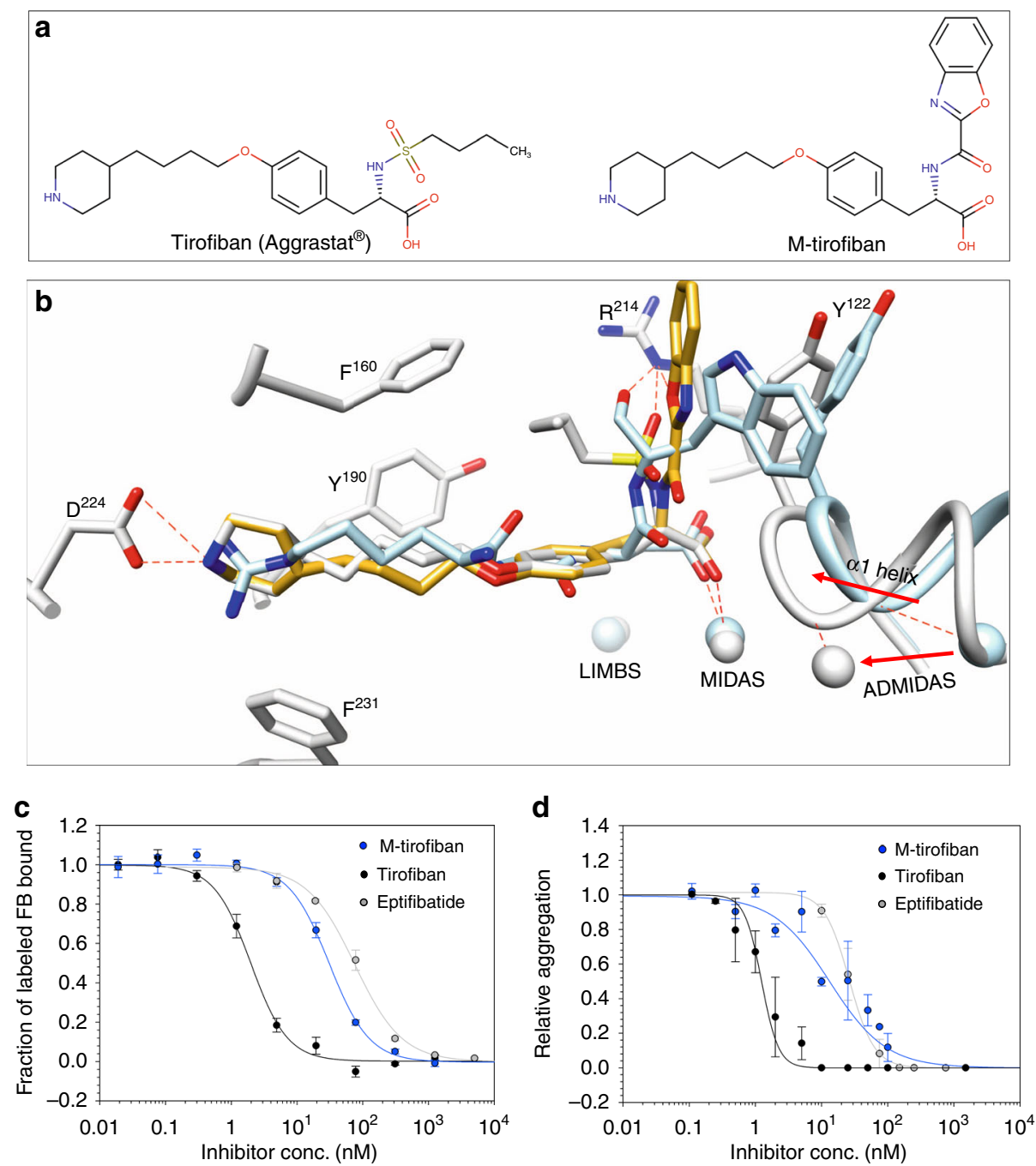

Fig. 7 Engineering and in vitro activities of $\mathbf{M}$-tirofiban. a Chemical structure of tirofiban and M-tirofiban (see also Supplemental Fig. 4). $\mathbf{b} \mathrm{A}$ model of bound $M$-tirofiban (gold) superposed on the structures of tirofiban/ $\alpha$ llb $\beta 3$ (gray, 2vdm.pdb) and the present $\alpha \vee \beta 3 / \mathrm{Hr} 10$ structure (light blue). The $\beta A$ domain of each was used in superposition. The metal ions at LIMBS, MIDAS, and ADMIDAS and relevant residues are shown in the respective colors. Contacts are shown as dotted red lines. See text for details. c Dose-response curves (mean $+/-$ s.e., $n=4$ experiments) showing displacement of labeled FB bound to preactivated $\alpha$ llb $\beta 3-K 562$ by tirofiban or M-tirofiban, yielding $I C_{50}$ s of $1.98+/-0.19 \mathrm{nM}$ and $30.9+/-3.3 \mathrm{nM}$, respectively. Displacement of labeled FB by eptifibatide (73.2 $\pm 7.0 \mathrm{nM}$; Fig. 2c) is added for comparison. $\mathbf{d}$ Dose-response curves (mean $+/-$ s.e.) showing effects of tirofiban and $\mathrm{M}$-tirofiban on human platelet aggregation from three different donors (three tirofiban and five M-tirofiban determinations) induced by ADP (20 $\mu \mathrm{M}$ ), yielding $\mathrm{IC}_{50} \mathrm{~S}$ of $1.41+/-0.23 \mathrm{nM}$ and $18.5+/-5.4 \mathrm{nM}$, respectively, in comparison with eptifibatide $(26.3+/-2.8 \mathrm{nM}$; Fig. $4 \mathrm{~b})$.

approach utilized low-affinity non-RGD small molecules that primarily engage the arginine pocket in $\mathrm{aIIb}^{42}$. These prevented $\mathrm{FeCl}_{3}$-induced thrombotic arterial occlusion in mice but its effects on clot retraction or bleeding were not reported ${ }^{43}$.

The present data show that the pure RGD-based aIIb $\beta 3$ antagonists $\mathrm{Hr} 10$ and M-tirofiban prevented thrombotic arterial and microvascular occlusion, and preserved hemostasis in humanized mice, thus demonstrating that partial agonism and antagonism of integrins are not inseparable. Pure orthosteric antagonism of $\alpha \mathrm{IIb} \beta 3$ offers significant advantages over the other approaches aimed at preserving hemostasis. First, by targeting the RGD-binding pocket of $\alpha \operatorname{IIb} \beta 3$ directly, such antagonists block binding of several prothrombotic ligands, some of which, such as

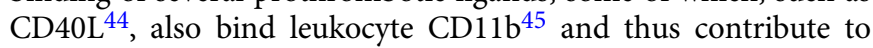
platelet-leukocyte interactions. Second, these high-affinity pure orthosteric inhibitors do not induce the conformational changes directly and block these changes when induced by inside-out integrin activation. Third, Hr10, a minor variant of a human natural ligand, is expected to be minimally immunogenic.
Whether certain preformed antibodies that recognize $\alpha I I b \beta 3$ in complex with tirofiban ${ }^{15}$ no longer do so when $\alpha \operatorname{IIb} \beta 3$ is bound by M-tirofiban or Hr10 can now be tested. Success in converting the partial agonist tirofiban into a pure antagonist using the present $\alpha \mathrm{V} \beta 3 / \mathrm{Hr} 10$ structure also underscores the primacy of the stable $\pi-\pi$ ligand- $\mathrm{W}^{1496} / \beta \mathrm{A}-\mathrm{Y}^{122}$ stacking interaction in preventing the activating global conformational change in $\alpha \operatorname{IIb} \beta 3$, and suggests that this approach may be applicable to engineering drug candidates targeting other integrins, where inadvertent conformational changes may also compromise patient safety.

The precise mechanism by which prevention of the agonistinduced conformational changes in $\alpha \operatorname{IIb} \beta 3$ by these pure orthosteric antagonists results in preservation of clot retraction is presently unknown, but there are several possibilities. Clot retraction occurs in response to the binding of polymeric fibrin to $\alpha I I b \beta 3$, thus linking the integrin to actomyosin 46 . When compared with $\mathrm{FB}$, polymeric fibrin binds $\alpha \operatorname{IIb} \beta 3$ with higher affinity ${ }^{47}$. So one possibility is that high affinity of the partial agonists is necessary to block fibrin- $\alpha \mathrm{IIb} \beta 3$ interaction and hence 

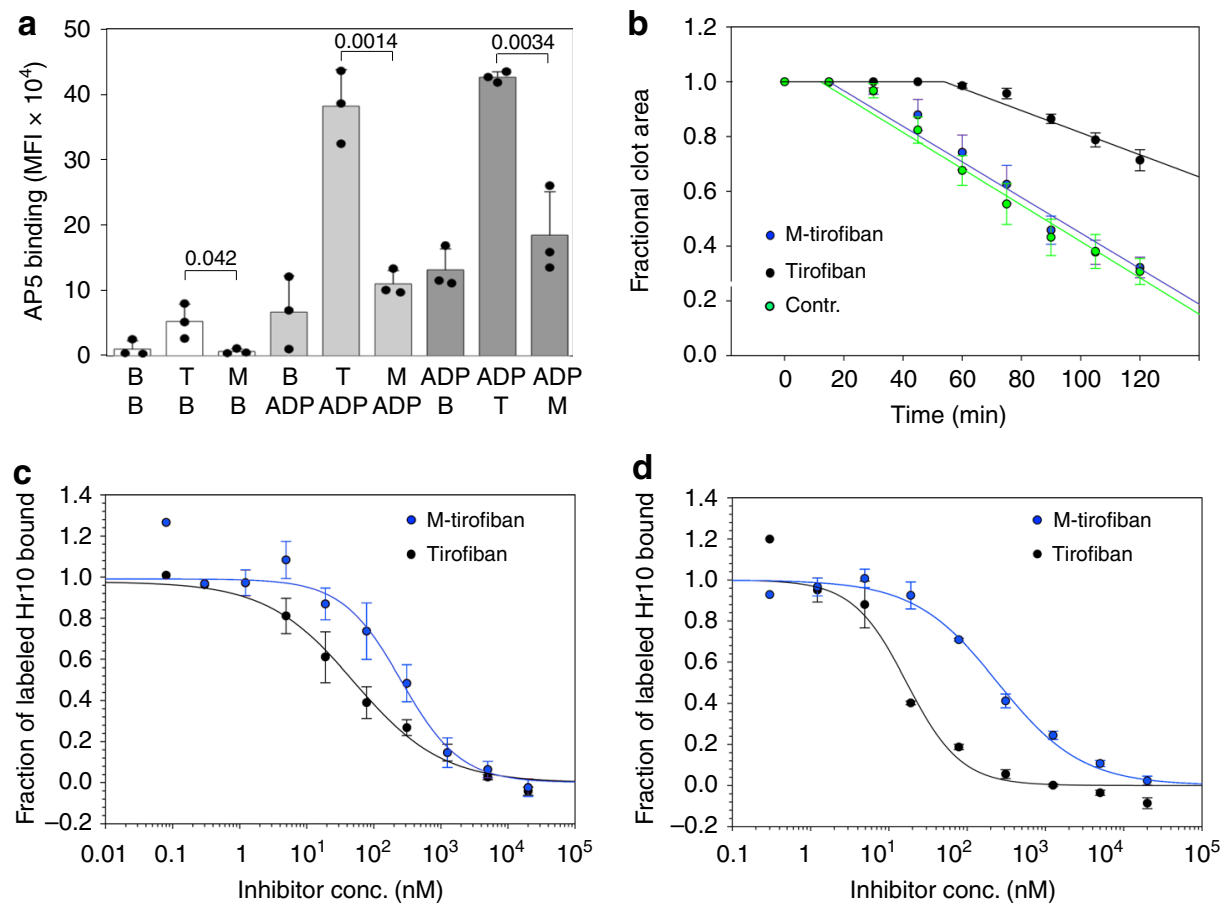

Fig. 8 M-tirofiban is a pure $\boldsymbol{\alpha} \mathbf{l l b} \boldsymbol{\beta} \mathbf{3}$ antagonist. a Histograms (mean + s.d., $n=3$ independent experiments) showing binding of $\mathrm{mAb} A P 5$ to human platelets in presence of buffer (B), tirofiban $(T ; 150 \mathrm{nM})$, and $M$-tirofiban $(M ; 1.5 \mu \mathrm{M}$; white histograms), and before (gray histograms) or after (dark gray histograms) addition of ADP $(5 \mu \mathrm{M})$. Numbers represent $p$ values (Student's t-test, two-tailed). No significant differences were found between buffer and M-tirofiban before $(p=0.273)$ or after ( $p=0.81$; both Student's $t$-test, two-tailed) ADP addition. $\mathbf{b}$ Kinetics of clot retraction in absence or presence of tirofiban, or M-tirofiban (mean +/-s.e., five experiments with three donors). Kinetics of clot retraction was not different between buffer control (contr.) and M-tirofiban ( $p=0.61$, F-test, two-tailed). c, d Dose-response curves (mean +/-s.e.) comparing displacement of Alexa488-labeled Hr10 binding to inactive $(\mathbf{c}, n=5)$ or mAb PT-25-activated $\alpha$ llb $\beta 3-\mathrm{K} 562(\mathbf{d}, n=3)$ by increasing concentrations of tirofiban or M-tirofiban in presence of physiologic concentrations of $\mathrm{Mg}^{2+}$ and $\mathrm{Ca}^{2+}\left(1 \mathrm{mM}\right.$ each). The respective $\mathrm{IC}_{50} \mathrm{~s}$ were $51.3+/-19.2 \mathrm{nM}$ and $257.2+/-88.0 \mathrm{nM}$ for inactive $\alpha$ llb $\beta 3$, and $16.9+/-$ $2.4 \mathrm{nM}$ and $247.1+/-29.3 \mathrm{nM}$ for active $\alpha$ llb $\beta 3$. The lower affinities of both compounds are explained by the requirement for more inhibitor to displace high affinity binding of $\mathrm{Hr} 10$ (compared to binding of FB in Fig. 7c) to $\alpha$ llb $\beta 3$.

clot retraction. This scenario is unlikely since Hr10 and eptifibatide have comparable affinities in blocking soluble FB binding to activated $\alpha \operatorname{IIb} \beta 3$ and in agonist-induced platelet aggregation. Preservation of clot retraction by the pure orthosteric antagonists could not be explained by a weaker affinity to inactive $\alpha \operatorname{IIb} \beta 3^{48}$, since affinities of the pure antagonists to inactive and active $\alpha \operatorname{IIb} \beta 3$ were similar. A recent study showed that fibrin binds $\alpha \operatorname{IIb} \beta 3$ even when all the RGD motifs in fibrin are deleted ${ }^{47}$, suggesting the presence of MIDAS-independent fibrin-binding sites $^{49}$. Since $\alpha \operatorname{IIb} \beta 3$ on non-activated platelets binds surfaceimmobilized fibrin ${ }^{50,51}$, it may also do so when occupied by Hr10 or M-tirofiban. It has been shown that aIIb 33 -dependent fibrin clot retraction kinetics correlates with intracellular protein tyrosine dephosphorylation, which is inhibited by binding of eptifibatide or abciximab to $\operatorname{aIb} \beta 3^{27}$. The availability of the pure orthosteric inhibitors of aIIb $\beta 3$ should now provide a new tool to further dissect the mechanisms linking integrin conformation to clot retraction.

The dual specificity of $\mathrm{Hr} 10$ to both $\beta 3$ integrins is shared with the drug abciximab ${ }^{52}$, a property thought to contribute to the long-term clinical benefits of abciximab in acute coronary syndrome ${ }^{53,54}$. In addition, dual specificity of abciximab to both $\beta 3$ integrins has shown a wide range of anticancer effects (reviewed in ref. ${ }^{55}$ ). For example, abciximab was effective at blocking tumor growth and angiogenesis through targeting the interaction of tumor cells with platelets and endothelial cells, in addition to direct effects on the tumor tissue ${ }^{56-59}$. Hr10 may thus offer an attractive clinical candidate in this case with minimal immunogenicity or bleeding risk.

\section{Methods}

Reagents and antibodies. Restriction and modification enzymes were obtained from New England Biolabs Inc. (Beverly, MA). Cell culture reagents were purchased from Invitrogen (San Diego, CA) or Fisher Scientific (Hampton, NH). The Fab fragment of mAb AP5 $5^{60}$ was prepared by papain digestion followed by anion exchange and size-exclusion chromatography. Hybridoma producing the $\beta 3$ conformation-insensitive mAb AP3 was bought from ATCC (catalogue \#ATCC $\mathrm{HB}^{\oplus}$-242) and antibody purified by affinity chromatography. Alexa Fluor 488-conjugated mAbs against human CD62P (catalogue \#sc-8419) and CD63 (catalogue\#sc-5275) were bought from Santa Cruz Biotechnology, Dallas, TX. Alexa Fluor647-conjugated anti-human CD42b mAb (catalogue \#FAB4067R) was from R\&D Systems, Minneapolis, MN. APC-labeled goat anti-mouse Fc-specific antibody (catalogue \#115-136-071) was from Jackson ImmunoResearch (West Grove, PA). Alexa Fluor-488-labeled $\mathrm{F}\left(\mathrm{ab}^{\prime}\right)_{2}$ fragment of mouse anti-human CD41a (catalogue \#555465) and Alexa Fluor-647 rat anti-mouse CD41a F(ab') (catalogue \#624101) were from BD Biosciences. The activating mAb PT-25-2 was a gift from Dr. Makoto Handa ${ }^{61}$. Eptifibatide and tirofiban were purchased from Millipore-Sigma (Burlington, MA). The plasmid pCDF5-Har, containing two copies of a UAG recognizing tRNA and the tRNA synthase (Har-Rs) for charging UAG tRNAs with Har, and the Escherichia coli strain B-95 $\Delta$ A containing a deletion of release factor 1 ( $p r f A$ ) and 95 synonymous TAG stop codon mutations, were kindly provided by Dr. Kensaku Sakamoto (RIKEN, Yokohama, Japan) ${ }^{62}$. L-Har and TRAP-6 were purchased from Bachem Americas, Inc. (Torrance, CA). ADP, collagen, ATP, Chrono-luminescence reagent, and human thrombin were purchased from Chrono-log (Havertown, PA).

Characterization of M-tirofiban. M-tirofiban was synthesized at the Organic Chemistry Collaborative Center, Columbia University Irving Medical Center, NY (Supplementary Fig. 4) using standard techniques. Its purity was $\geq 95 \%$ as determined by liquid chromatography-mass spectrometry performed on two different instruments, a Shimadzu 2010A and a Shimadzu 2020 UFLC mass spectrometer at wavelengths 220 and $254 \mathrm{~nm}$, using a Waters Sunfire column $(\mathrm{C} 18,5 \mu \mathrm{m}, 2.1 \mathrm{~mm} \times 50 \mathrm{~mm}$, a linear gradient from 5 to $100 \% \mathrm{~B}$ over $15 \mathrm{~min}$, then $100 \%$ B for $2 \min \left(A=0.1 \%\right.$ formic acid $+\mathrm{H}_{2} \mathrm{O}, \mathrm{B}=0.1 \%$ formic acid $\left.+\mathrm{CH}_{3} \mathrm{CN}\right)$, flow rate $0.2000 \mathrm{ml} / \mathrm{min}) .{ }^{1} \mathrm{H}$ NMR and ${ }^{13} \mathrm{C}$ NMR spectra were recorded on an 
a
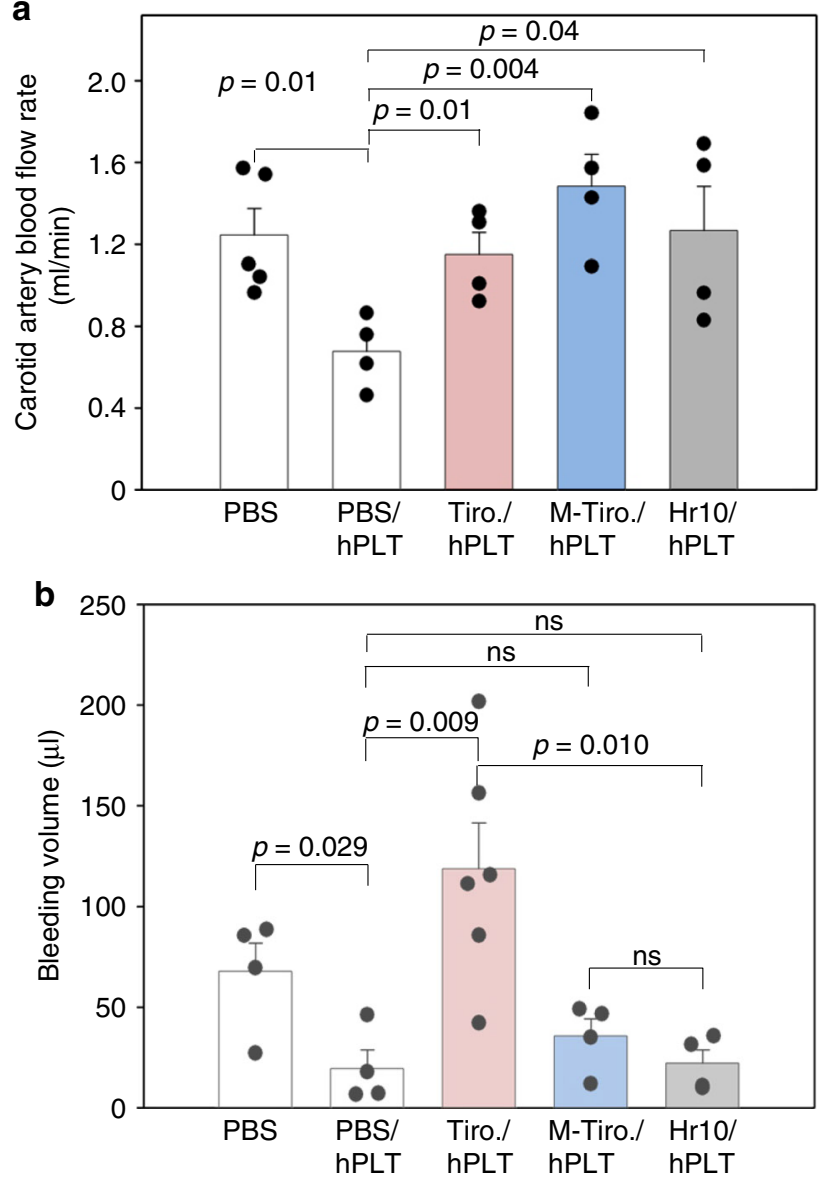

C

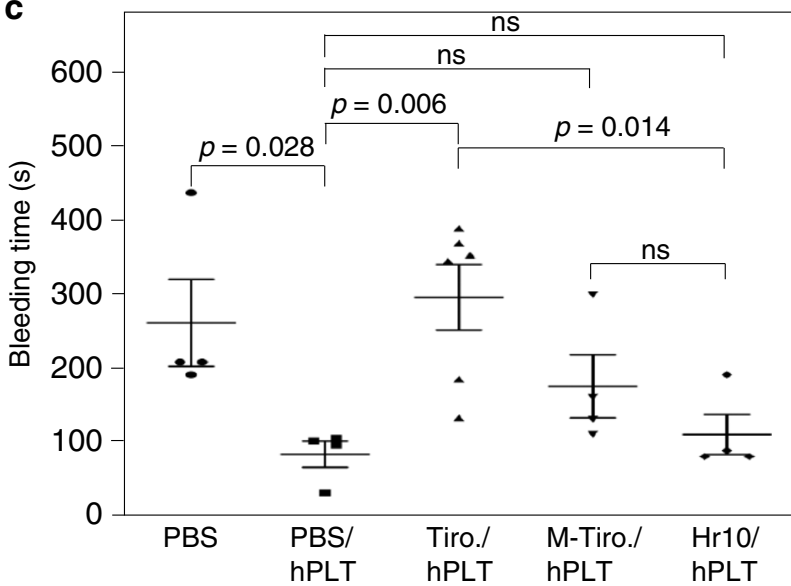

Fig. 9 In vivo activities of $\mathbf{M}$-tirofiban. a Histograms (mean + s.e.) showing carotid artery blood flow over the 40-min observation period following redoxinduced arterial injury. vWFRH/RH NSG male mice were either uninfused (PBS; $n=5)$ or infused with human platelets (hPLT) plus PBS $(n=4)$, tirofiban (Tiro; $n=4)$, M-tirofiban (M-Tiro.; $n=4)$, or Hr10 $(n=4)$. b Blood loss (mean + s.e.) in $\mathrm{VWF}^{R H / R H} \mathrm{NSG}$ male mice uninfused (PBS; $\left.n=4\right)$ or infused with hPLT plus PBS $(n=4)$, tirofiban (Tiro.; $n=6), M$-tirofiban (M-Tiro.; $n=4)$, or $\operatorname{Hr} 10(n=4)$. $p$ values are indicated. c Bleeding time analysis (mean $+/-$ s.e.) in $v W F$ RH/RH NSG male mice treated as in Fig. 6 b. Statistical tests by Student's $t$-test, two-tailed; ns, not significant.

Agilent $400-\mathrm{MR}$ 400-MHz NMR spectrometer, operating at $400 \mathrm{MHz}\left({ }^{1} \mathrm{H}\right.$ NMR) and $101 \mathrm{MHz}\left({ }^{13} \mathrm{C}\right.$ NMR). Chemical shifts are given in units $\delta(\mathrm{ppm})$. The proton resonance of residual solvent ( $\delta 3.31$ for $d_{4}$-methanol) was used as the internal reference for ${ }^{1} \mathrm{H}$ NMR spectra. The chemical shifts of ${ }^{13} \mathrm{C}$ spectra are reported relative to the carbon signal of $d_{4}$-methanol at $\delta 49.00$. All reagents and solvents were used as received from major commercial suppliers, such as Sigma-Aldrich, Fisher Scientific, and Alfa Aesar without further purification. All air- or moisturesensitive reactions were run under an atmosphere of argon in oven-dried glassware.

Plasmids, mutagenesis, protein expression, and purification. Human $\alpha \mathrm{V} \beta 3$ ectodomain and hFN10 were expressed in insect cells and BL21-DE3 bacteria, respectively, and each purified by affinity chromatography followed by gel filtration $^{20}$. Hr10 was generated by replacing $\mathrm{S}^{1500} \mathrm{~K}$ in hFN10 with a glycine residue and introducing a TAG stop codon at position 1493 by PCR-based mutagenesis with the Quick-change kit (Agilent Technologies). Hr10 cDNA was cloned into the bacterial expression plasmid pET1la and verified by DNA sequencing. A bacterial stock of $E$. coli strain B-95 $\triangle$ A containing plasmids pCDF5Har and pET-11a/Hr10 grown in LB media supplemented with $5 \mathrm{mM} \mathrm{L}-\mathrm{Har}$, $50 \mu \mathrm{g} / \mathrm{ml}$ kanamycin (pCDF5-Har), and $100 \mu \mathrm{g} / \mathrm{ml}$ ampicillin (pET-11a) was prepared and used to express Hr10 protein. Bacterial cultures at $\sim 0.5$ absorbance $(600 \mathrm{~nm})$ were induced with $0.3 \mathrm{mM}$ IPTG and grown for $8 \mathrm{~h}$ at room temperature (RT). Hr10 was purified as for hFN10 and purity assessed by fractionation on gradient sodium dodecyl sulfate-polyacrylamide gel electrophoresis (SDS-PAGE) gels followed by Coomassie staining.

Cell lines, cell culture, and transfection. Human K562 cells stably expressing $\alpha V \beta 3$ ( $\alpha$ V $\beta 3$-K562) have been described ${ }^{20}$. K562 cells stably expressing $\alpha I I b \beta 3$ ( $\alpha$ IIb $33-K 562$ ) were kindly provided by Dr. Jennifer Cochran (Stanford University, $\mathrm{CA})^{63}$. Cultured K562 were maintained in Iscove's modified Dulbecco's medium plus G418 $(0.5-1.0 \mathrm{mg} / \mathrm{ml})$, supplemented with $10 \%$ fetal calf serum, $2 \mathrm{mM} \mathrm{L}$-glutamine, and penicillin and streptomycin.

Ligand binding and flow cytometry. For ligand binding assays, $\alpha \mathrm{II} \beta 3-\mathrm{K} 562$ or $\alpha \mathrm{V} \beta 3$-K562 cells $\left(1 \times 10^{6}\right)$ were suspended in $100 \mu \mathrm{l}$ of buffer A $(20 \mathrm{mM}$ Hepes, $150 \mathrm{mM} \mathrm{NaCl}, \mathrm{pH} 7.4$, containing $0.1 \%[\mathrm{w} / \mathrm{v}]$ bovine serum albumin, and $1 \mathrm{mM}$ each of $\mathrm{MgCl}_{2}$ and $\mathrm{CaCl}_{2}$ ) and incubated first with Alexa-647-labeled $\mathrm{Hr} 10$ or hFN10 (each at $3-10 \mu \mathrm{g} / \mathrm{ml}$ ) for $30 \mathrm{~min}$ at RT. For competition studies, $100 \mu \mathrm{l}$ of mAb PT-25-activated aIIb 33 -K562 $\left(1 \times 10^{6}\right)$ were incubated for $30 \mathrm{~min}$ at RT with serially diluted concentrations of unlabeled $\mathrm{Hr} 10, \mathrm{hFN} 10$, or eptifibatide in the presence of $0.5 \mu \mathrm{M}$ Alexa647-conjugated FB. Cells were washed with $4 \mathrm{ml}$ of buffer $\mathrm{A}$ and centrifuged for $5 \mathrm{~min}$ at $525 \times \mathrm{g}$, resuspended, fixed in $2 \%$ paraformaldehyde, and analyzed using FACSCalibur or BD-LSRII flow cytometers (BD Biosciences). Ligand binding was expressed as mean fluorescence intensity (MFI), as determined using FlowJo software. Mean and s.d. from independent experiments were calculated and compared using Student's $t$-test.

Platelet aggregation and ATP secretion. Platelet aggregation and ATP secretion in whole blood were measured using a Chrono-Log model 700 two-channel lumiaggregation system following the manufacturer's instructions. Human blood samples were obtained from healthy volunteers, who provided written informed consent under a study that complied with all relevant ethical regulations and approved by the Human Subjects Committee at the Massachusetts General Hospital in accord with the Helsinki Principles. Blood was drawn directly into 3.2\% sodium citrate and used within $3 \mathrm{~h}$. None of the subjects were taking any medications for at least 10 days prior. For impedance aggregation measurements, $0.5 \mathrm{ml}$ of whole blood was mixed with $0.5 \mathrm{ml}$ physiologic saline supplemented with inhibitors and incubated at $37^{\circ} \mathrm{C}$ for 5 min without stirring. Measurements were performed with stirring at $1200 \mathrm{rpm}$ at $37^{\circ} \mathrm{C}$. Values for each data point represent impedance measurements following application of agonist, integrated over $5 \mathrm{~min}$. Data points for an individual dose curve were serially collected from a single draw and analyzed with SigmaPlot (Systat Software, San Jose, CA) using a least-square fit to a logistic curve, and the $\mathrm{IC}_{50}$ values determined from the fitted parameter. ATP secretion proceeded similarly except that $0.45 \mathrm{ml}$ of whole blood were added to $0.45 \mathrm{ml}$ of saline supplemented with various concentrations of $\mathrm{Hr} 10$ or eptifibatide to produce the desired concentration in $1.0 \mathrm{ml}$. Following incubation for $5 \mathrm{~min}$ at $37^{\circ} \mathrm{C}, 100 \mu \mathrm{l}$ of Chrono-lume reagent was added and aggregation initiated. The luminescence signal was quantified with a non-aggregated sample supplemented with an ATP standard.

Binding of mAbs. $\alpha \mathrm{V} \beta 3$ - or $\alpha \mathrm{IIb} \beta 3-\mathrm{K} 562$ cells $\left(0.5 \times 10^{6}\right.$ in $100 \mu \mathrm{l}$ of buffer A) were incubated in the absence or presence of unlabeled Hr10 or eptifibatide, each at $1.5 \mu \mathrm{M}$, for $20 \mathrm{~min}$ at RT. Alexa647-labeled AP5 Fab or unlabeled LIBS-1 $\mathrm{mAb}$ (each to $10 \mu \mathrm{g} / \mathrm{ml}$ ) were added, and cells incubated for an additional $30 \mathrm{~min}$ before washing with $4 \mathrm{ml}$ of buffer A and centrifugation for $5 \mathrm{~min}$ at $525 \times \mathrm{g}$. APC-labeled goat anti-mouse Fc-specific antibody (at $10 \mu \mathrm{g} / \mathrm{ml}$ ) was added to LIBS-1-bound cells for an additional $30 \mathrm{~min}$ at $4{ }^{\circ} \mathrm{C}$. Afterward, cells were washed and processed for flow cytometry. To quantify ADP-induced expression of CD62P and CD63 on human platelets, ADP (at $20 \mu \mathrm{M}$ ) was added to $100 \mu \mathrm{l}$ of $3.2 \%$ sodium citrate whole blood that was preincubated with Hr10 or eptifibatide (at $1.5 \mu \mathrm{M}$ each) for $5 \mathrm{~min}$ at RT. Untreated anticoagulated whole blood served as negative control. Alexa488-labeled anti-CD62P or anti-CD63 mAbs (at $10 \mu \mathrm{g} / \mathrm{ml}$ ) plus Alexa647-labeled anti-CD42b mAb (at $10 \mu \mathrm{g} / \mathrm{ml}$ ) were then added to the blood samples for $20 \mathrm{~min}$ at RT. Cells were washed, fixed in $2 \%$ paraformaldehyde, and $\mathrm{CD} 62 \mathrm{P}$ and CD63 expression analyzed by flow cytometry in the CD42b-positive 
population. Mean and s.d. from three independent experiments were compared using Student's $t$-test.

Crystallography, structure determination, and refinement. Human $\alpha \mathrm{V} \beta 3$ ectodomain was purified and crystallized by the hanging drop method as previously described ${ }^{16}$. Hr 10 was soaked for 3 weeks into the preformed $\alpha \mathrm{V} \beta 3$ crystals at $1.5 \mathrm{mM}$ in the crystallization well solution containing $1 \mathrm{mM} \mathrm{Mn}{ }^{2+}$. Crystals were harvested in 12\% PEG 3500 in $100 \mathrm{mM}$ sodium acetate, $\mathrm{pH} 4.5,800 \mathrm{mM} \mathrm{NaCl}$ plus $1 \mathrm{mM} \mathrm{Mn}{ }^{2+}$, cryoprotected by addition of glycerol in $2 \%$ increments up to $24 \%$ final concentration, and then flash-frozen in liquid nitrogen. Diffraction data were collected at ID-19 of APS, indexed, integrated, scaled by HKL2000 ${ }^{64}$, and solved by molecular replacement in PHASER using 3ije.pdb and $1 \mathrm{fnf} . \mathrm{pdb}$ as the search model. The structure was refined with Phenix using default restraints, positional and individual temperature factor, and translation-liberation-screw. Automatic optimization of X-ray and stereochemistry, and Ramachandran restriction were used in the final cycle. Data collection and refinement statistics are shown in Supplementary Table 1. The coordinates and structure factors of $\alpha \mathrm{V} \beta 3 / \mathrm{Hr} 10$ have been deposited in the Protein Data Bank under accession code 6NAJ. Structural illustrations were prepared with Chimera.

\section{Generation of vWFR1326H knock-in NSG mice. CRISPR/Cas 9 technology was} used to generate the $\mathrm{vWF}^{R 1326 H}$ knock-in (KI) mice of NSG background with a mutation of specific nucleotide at the exon 28 of the mouse vWF gene, resulting in replacing the arginine (codon CGT) at amino acid no. 1326 by histidine (codon CAT). An sgRNA was designed according to the online resources, the sgRNA Designer: CRISPRko and the Cas-OFFinder, and the sgRNAs with less than three mismatches and less than 25 off-target sites were used. The sgRNA target sequence was $5^{\prime}$ - CTTGAGCTCAA GGTAGGCAC-3'. The histidine codon was repaired into the gene with a single-stranded oligo. (5'-ACATCTCTCAGAAGCGCATCCG CGTGGCAGTGGTAGAGTACCATGATGGATCCCATGCTTATCTTGAGCTC AAGGCCCGGAAGCGACCCTCAGAGCTTCGGCGCATCACCAGCCAGA TTA-3'(Integrated DNA technologies, Inc.). Preparation of sgRNA and Cas9 RNA for pronucleus microinjection followed the instructor's manual (AmpliCapMaxTM T7 High Yield Message Maker kit). Pronuclear microinjection was performed on fertilized eggs from NSG mice. Genotyping of founder mice was performed by PCR, TA-cloning, followed by Sanger DNA sequencing. The primer

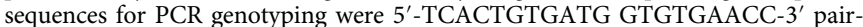
ing with $5^{\prime}$-CTGACTATCTC ATCTCTTC- $3^{\prime}$. PCR condition was $95^{\circ} \mathrm{C}, 5 \mathrm{~min}$, followed by 35 cycles of $95^{\circ} \mathrm{C}, 30 \mathrm{~s} ; 55^{\circ} \mathrm{C}, 30 \mathrm{~s}$; and $72^{\circ} \mathrm{C}, 30 \mathrm{~s}$, and a final extension at $72^{\circ} \mathrm{C}, 7 \mathrm{~min}$. TA-cloning followed the instructor's manual (T3 Cloning kit; ZGene Biotech Inc.). Production of the vWF R1326H KI NSG mice was carried out by the Transgenic Mouse Model Core Facility.

Clot retraction. A total of $750 \mu \mathrm{l}$ of Tyrode's buffer $(127 \mathrm{mM} \mathrm{NaCl}, 5 \mathrm{mM} \mathrm{KCl}$, $1.8 \mathrm{mM} \mathrm{NaH}_{2} \mathrm{PO}_{4}, 1 \mathrm{mM} \mathrm{MgCl}$, $25 \mathrm{mM} \mathrm{NaHCO}_{3}, 10 \mathrm{mM}$ glucose, $0.1 \%$

$\mathrm{NaHCO} 3, \mathrm{pH} 7.4$ ) supplemented with inhibitor was mixed in a glass culture tube with $200 \mu \mathrm{l}$ of human PRP and $5 \mu \mathrm{l}$ red blood cells. Clotting was initiated by addition of $50 \mu \mathrm{l}$ thrombin at 10 units $/ \mathrm{ml}$ in saline and a sealed Pasteur pipette secured in the tube center. Digital photographs of the experiment were taken at 15 -min intervals over $2 \mathrm{~h}$. Images were analyzed with ImageJ software to determine the area occupied by the clot and plasma. Plots of the relative areas and linear regressions were performed with SigmaPlot (Systat Software, San Jose, CA).

Cremaster arteriole laser injury model. Human blood was collected in $0.129 \mathrm{M}$ sodium citrate $(10: 1 \mathrm{vol} / \mathrm{vol})$. Blood was obtained from healthy donors who provided written informed consent under a protocol that complied with all relevant ethical regulations and approved by the Children's Hospital of Philadelphia (CHOP) Internal Review Board in accord with the Helsinki Principles. PRP was separated after centrifugation $(200 \times g, 10 \mathrm{~min})$ at RT. The platelets were isolated from PRP, and prostaglandin E1 (Sigma-Aldrich) added to a final concentration of $1.0 \mu \mathrm{M}$. Platelets were pelleted by centrifugation $(800 \times \mathrm{g}, 10 \mathrm{~min})$ at RT. The pellet was washed in calcium-free Tyrode's buffer $(134 \mathrm{mM} \mathrm{NaCl}, 3 \mathrm{mM}$ $\mathrm{KCl}, 0.3 \mathrm{mM} \mathrm{NaH} \mathrm{PO}_{4}, 2 \mathrm{mM} \mathrm{MgCl}_{2}, 5 \mathrm{mM}$ HEPES, $5 \mathrm{mM}$ glucose, $0.1 \%$ $\mathrm{NaHCO}_{3}$, and $1 \mathrm{mM}$ EGTA, pH 6.5), and resuspended in CATCH buffer (phosphate-buffered saline (PBS) containing $1.5 \%$ bovine serum albumin, $1 \mathrm{mM}$ adenosine, $2 \mathrm{mM}$ theophylline, $0.38 \%$ sodium citrate, all from Sigma-Aldrich). Platelet counts were determined using a HemaVet counter (Drew Scientific). Animal experiments complied with all relevant ethical regulations, and were approved by the IACUC of the CHOP, and all investigators adhered to NIH guidelines for the care and use of laboratory animals. vWF ${ }^{R H / R H}$ NSG male mice were studied after being anesthetized using sodium pentobarbital $(80 \mathrm{mg} / \mathrm{kg})$ injected intraperitoneally and maintained under anesthesia with the same anesthetic delivered via a catheterized jugular vein at $5 \mathrm{mg} / \mathrm{ml}$ throughout the experiment. The thrombinmediated microvascular injury model was performed as described ${ }^{65}$. Briefly, the cremaster muscle was surgically exteriorized and continuously superfused with PBS containing $0.9 \mathrm{mM} \mathrm{CaCl}_{2}$ and $0.49 \mathrm{mM} \mathrm{MgCl}_{2}$ maintained at $37^{\circ} \mathrm{C}$ throughout the entire experiment. Human platelets $\left(4 \times 10^{8} /\right.$ mouse) were infused into the jugular vein with Alexa-488-labeled mouse anti-human $\mathrm{CD} 41 \mathrm{~F}\left(\mathrm{ab}^{\prime}\right)_{2}$ followed by Alexa Fluor-647 rat anti-mouse CD41 $\mathrm{F}\left(\mathrm{ab}^{\prime}\right)_{2}$ (each at 3-4 $\mu \mathrm{g} / 20 \mathrm{gm}$ mouse) to detect endogenous mouse platelets. Microvascular injury was induced with an SRS NL100 pulsed nitrogen dye laser $(440 \mathrm{~nm})$ focused on the vessel wall through the microscope objective. Each injury was followed for $3 \mathrm{~min}$. Eptifibatide was used at $0.2 \mu \mathrm{g} / \mathrm{g}$ mouse body weight (BW; equivalent to the clinically effective dose ${ }^{23}$ ) and Hr10 was used at an equimolar concentration $(2.4 \mu \mathrm{g} / \mathrm{g} \mathrm{BW})$. Drugs were infused 5 min prior to laser injury via the jugular vein. Pre and post drug measurements were made in the same animal. Wide-field images of the dynamic accumulation of fluorescently labeled platelets within the growing thrombi were recorded using a Hamamatsu ORCA Flash 4.0 V3 CMOS camera (Hamamatsu, Japan) coupled to an Excelitas X-Cite XLED light source. The microscope, cameras, and light sources were all controlled using Slidebook 6.0 software (Intelligent Imaging Innovations). Intensity of the fluorescent signal was used to measure incorporated platelets. Eight injuries were made in each of four mice per group. Studies in each animal were completed within $1 \mathrm{~h}$ after drug infusion to avoid the subsequent variable clearance of human platelets by host macrophages ${ }^{66}$.

Carotid artery thrombosis injury studies. Redox-induced thrombosis was initiated in anesthetized $\mathrm{vWF}^{R H / R H} \mathrm{NSG}$ post human platelet infusion $\left(8 \times 10^{8}\right.$ human platelets) by Rose Bengal photochemical injury to the carotid artery as described ${ }^{67}$. Briefly, mice were first injected with $100 \mu \mathrm{l}$ of PBS (Gibco) or PBS containing tirofiban, M-tirofiban or Hr10 via the jugular vein. Rose Bengal $(50 \mathrm{mg} / \mathrm{kg}$, SigmaAldrich) was then infused and a miniature Doppler flow probe (Model 0.5VB; Transonic Systems) was positioned around the artery. After 1 min of measuring baseline flow, a $540 \mathrm{~nm}$ laser was targeted to the carotid artery to induce an occlusive thrombus and blood flow was monitored for $40 \mathrm{~min}$. Area under the curve of total blood flow was calculated. After $40 \mathrm{~min}$ of recording, the mice were euthanized.

Tail bleeding studies. Pentobarbital-anesthetized vWF ${ }^{R H / R H}$ NSG mice were infused retro-orbitally with $8 \times 10^{8}$ washed human platelets in a final volume of $200 \mu \mathrm{l}$ (so that $\sim 40 \%$ of circulating platelets were human). After $5 \mathrm{~min}$, PBS containing $0.1 \%$ DMSO, or equipotent amounts of eptifibatide $(0.2 \mu \mathrm{g} / \mathrm{g} \mathrm{BW}), \mathrm{Hr} 10$ $(2.4 \mu \mathrm{g} / \mathrm{g} \mathrm{BW})$, tirofiban $(0.025 \mu \mathrm{g} / \mathrm{g} \mathrm{BW})$, or M-tirofiban $(0.32 \mu \mathrm{g} / \mathrm{g} \mathrm{BW})$ in the same buffer were administered intravenously. After another $5 \mathrm{~min}$, the tip of the mouse tail $(8 \mathrm{~mm})$ was amputated with a sharp razor blade and the tail placed in a collection tube containing sterile water at $37^{\circ} \mathrm{C}$. To measure the total blood loss, the hemoglobin level in the water was quantified ${ }^{68}$ with the following modifications: the hemolyzed whole blood/water mixture was centrifuged at $21,000 \times g$ in countertop Sorvall Legend Micro21 centrifuge (Thermo scientific) for 5 min. A total of $20 \mu \mathrm{l}$ of clarified, stroma-free supernatant were diluted 10 -fold in a 96 -wel microplate (Corning) and light absorbance was measured at $575 \mathrm{~nm}$ (Spectramax190 plate reader, Molecular Devices). Blood loss during the 10-min window was measured based on standard curve previously obtained. Total bleeding time over the 10 -min study was also recorded.

Platelet clearance studies. vWF ${ }^{R H} / R H$ NSG mice were anesthetized, injected with human platelets and drugs as in the photochemical carotid artery injury studies. Retro-orbital blood collection was performed preplatelet and drug infusions, and at time points. Collected blood was determined by flow cytometry using a combination of PE-conjugated rat anti-mouse CD41a and APC-conjugated mouse antihuman CD41a as above. Percent survival of human and mouse platelets was calculated. All statistics were done using nonparametric t-tests.

Statistical calculations. Dose-response experiments for whole blood aggregation and binding to K562 cells were conducted at least three times. Curve-fitting and statistical calculations were performed in SigmaPlot. The data points from each replicate were individually fit to a sigmoidal function to determine the minimum and maximum values for scaling. Data scaled to a maximum of 1 and a minimum of 0 were combined and again fit to a sigmoidal curve to determine the $\mathrm{IC}_{50}$ value. The standard error for the $\mathrm{IC}_{50}$ estimate was calculated using the reduced $\chi^{2}$ method. $p$ values comparing $\mathrm{IC}_{50}$ s from different inhibitors were determined using the global fit function in SigmaPlot. The two data sets were fit with all parameters separate and again where the $\mathrm{IC}_{50}$ value is shared between the data sets Fisher's $F$ statistic was calculated from the residual sum of squares and degrees of freedom for the unshared $\left(\mathrm{SS}_{\mathrm{un}}, \mathrm{DF}_{\mathrm{un}}\right)$ and shared $\left(\mathrm{SS}_{\mathrm{sh}}, \mathrm{DF}_{\mathrm{sh}}\right)$ with the equation $F=\left(\left(\mathrm{SS}_{\mathrm{sh}}-\mathrm{SS}_{\mathrm{un}}\right) /\left(\mathrm{DF}_{\mathrm{sh}}-\mathrm{DF}_{\mathrm{un}}\right)\right) /\left(\mathrm{SS}_{\mathrm{un}} / \mathrm{DF}_{\mathrm{un}}\right)$ and the $p$ value obtained from the $F$ distribution. Linear regression fits to data from clot retraction experiments proceeded similarly. The Holm-Sidak test following one-way analysis of variance (alpha $=5.0 \%$ ) was used to assess if the differences in human platelet accumulation in thrombi between $\mathrm{Hr} 10$ and eptifibatide-treated mice were significant. Each time point was analyzed individually, without assuming a consistent standard deviation. For the bleeding studies, the data passed the Shapiro-Wilk normality test and hence compared using the Student's $t$-test. Number of mice used for the bleeding studies is derived from the expectation of a large difference between treatments with eptifibatide or tirofiban, where only $5 \%$ of mice are expected to preserve normal hemostasis, and Hr10 or M-tirofiban, where we expect $80 \%$ would preserve normal hemostasis based on our clot retraction studies. With these assumptions four animals per group will produce a significance level of 0.05 with $90 \%$ statistical power ${ }^{69}$. 
Reporting summary. Further information on research design is available in the Nature Research Reporting Summary linked to this article.

\section{Data availability}

All relevant data are included in the paper and/ or its supplementary information files. The source data of Figs. 2a-d; 4a-c, e, f; 5b, c; 6a, b; 7c, d; 8a-d; 9a-c; and Supplementary Figs. 3 and 5 are provided in a Source Data file. The atomic coordinates and structure factors for the reported crystal structure of $\alpha \mathrm{V} \beta 3 / \mathrm{Hr} 10$ complex have been deposited in the Protein Data Bank (PDB) under the accession code 6NAJ. [http://www.rcsb.org/pdb/ results/results.do?tabtoshow $=$ Unreleased\&qrid $=\mathrm{AD} 6 \mathrm{~A} 3 \mathrm{C} 5 \mathrm{C}]$, where they can be obtained free of charge.

Received: 4 April 2019; Accepted: 6 December 2019; Published online: 21 January 2020

\section{References}

1. Yang, $H$. et al. Fibrinogen and von Willebrand factor-independent platelet aggregation in vitro and in vivo. J. Thromb. Haemost. 4, 2230-2237 (2006).

2. Coller, B. S. \& Shattil, S. J. The GPIIb/IIIa (integrin alphaIIbbeta3) odyssey: a technology-driven saga of a receptor with twists, turns, and even a bend. Blood 112, 3011-3025 (2008)

3. Hantgan, R. R. \& Mousa, S. A. Inhibition of platelet-mediated clot retraction by integrin antagonists. Thromb. Res. 89, 271-279 (1998).

4. Tutwiler, V., Wang, H., Litvinov, R. I., Weisel, J. W. \& Shenoy, V. B. Interplay of platelet contractility and elasticity of fibrin/erythrocytes in blood clot retraction. Biophys. J. 112, 714-723 (2017).

5. Benjamin, E. J. et al. Heart disease and stroke statistics-2017 update: a report from the American Heart Association. Circulation 135, e146-e603 (2017)

6. Quencer, K. B. \& Oklu, R. Hemodialysis access thrombosis. Cardiovasc. Diagn. Ther. 7, S299-S308 (2017).

7. Ponticelli, C., Moia, M. \& Montagnino, G. Renal allograft thrombosis. Nephrol. Dial. Transpl. 24, 1388-1393 (2009).

8. Lavergne, M., Janus-Bell, E., Schaff, M., Gachet, C. \& Mangin, P. H. Platelet integrins in tumor metastasis: do they represent a therapeutic target? Cancers (Basel) 9, https://doi.org/10.3390/cancers9100133 (2017).

9. Bosch, X., Marrugat, J. \& Sanchis, J. Platelet glycoprotein IIb/IIIa blockers during percutaneous coronary intervention and as the initial medical treatment of non-ST segment elevation acute coronary syndromes. Cochrane Database Syst. Rev., CD002130, https://doi.org/10.1002/14651858.CD002130. pub4 (2013).

10. Ndrepepa, G. et al. Correlates of poor outcome among patients with bleeding after coronary interventions. Coron. Artery Dis. 25, 456-462 (2014).

11. Ley, K., Rivera-Nieves, J., Sandborn, W. J. \& Shattil, S. Integrin-based therapeutics: biological basis, clinical use and new drugs. Nat. Rev. Drug Discov. 15, 173-183 (2016).

12. Franchi, F. \& Angiolillo, D. J. Novel antiplatelet agents in acute coronary syndrome. Nat. Rev. Cardiol. 12, 30-47 (2015).

13. McFadyen, J. D. \& Peter, K. Novel antithrombotic drugs on the horizon: the ultimate promise to prevent clotting while avoiding bBleeding. Circ. Res. 121, 1133-1135 (2017).

14. Hantgan, R. R. \& Stahle, M. C. Integrin priming dynamics: mechanisms of integrin antagonist-promoted alphaIIbbeta3:PAC-1 molecular recognition. Biochemistry 48, 8355-8365 (2009).

15. Bougie, D. W. et al. Acute thrombocytopenia after treatment with tirofiban or eptifibatide is associated with antibodies specific for ligand-occupied GPIIb/ IIIa. Blood 100, 2071-2076 (2002).

16. Xiong, J. P. et al. Crystal structure of the extracellular segment of integrin alpha Vbeta3. Science 294, 339-345 (2001)

17. Xiong, J. P. et al. Crystal structure of the extracellular segment of integrin alpha Vbeta3 in complex with an Arg-Gly-Asp ligand. Science 296, 151-155 (2002).

18. Springer, T. A., Zhu, J. \& Xiao, T. Structural basis for distinctive recognition of fibrinogen gammaC peptide by the platelet integrin alphaIIbbeta3. J. Cell Biol. 182, 791-800 (2008)

19. Arnaout, M. A., Goodman, S. L. \& Xiong, J. P. Structure and mechanics of integrin-based cell adhesion. Curr. Opin. Cell Biol. 19, 495-507 (2007).

20. Van Agthoven, J. F. et al. Structural basis for pure antagonism of integrin alphaVbeta3 by a high-affinity form of fibronectin. Nat. Struct. Mol. Biol. 21, 383-388 (2014).

21. Paladino, A., Civera, M., Belvisi, L. \& Colombo, G. High affinity vs. native fibronectin in the modulation of alphavbeta 3 integrin conformational dynamics: insights from computational analyses and implications for molecular design. PLoS Comput. Biol. 13, e1005334 (2017).
22. Richards, J. et al. Engineered fibronectin type III domain with a RGDWXE sequence binds with enhanced affinity and specificity to human alphavbeta3 integrin. J. Mol. Biol. 326, 1475-1488 (2003).

23. Holmes, M. B., Sobel, B. E. \& Schneider, D. J. Variable responses to inhibition of fibrinogen binding induced by tirofiban and eptifibatide in blood from healthy subjects. Am. J. Cardiol. 84, 203-207 (1999).

24. Massberg, S., Mueller, I., Besta, F., Thomas, P. \& Gawaz, M. Effects of 2 different antiplatelet regimens with abciximab or tirofiban on platelet function in patients undergoing coronary stenting. Am. Heart J. 146, E19 (2003).

25. Elaib, Z. et al. Full activation of mouse platelets requires ADP secretion regulated by SERCA3 ATPase-dependent calcium stores. Blood 128, 1129-1138 (2016)

26. Leon, C. et al. Megakaryocyte-restricted MYH9 inactivation dramatically affects hemostasis while preserving platelet aggregation and secretion. Blood 110, 3183-3191 (2007).

27. Osdoit, S. \& Rosa, J. P. Fibrin clot retraction by human platelets correlates with alpha(IIb)beta(3) integrin-dependent protein tyrosine dephosphorylation. J. Biol. Chem. 276, 6703-6710 (2001).

28. Haling, J. R., Monkley, S. J., Critchley, D. R. \& Petrich, B. G. Talin-dependent integrin activation is required for fibrin clot retraction by platelets. Blood 117 1719-1722 (2011)

29. Tucker, K. L., Sage, T. \& Gibbins, J. M. Clot retraction. Methods Mol. Biol. 788, 101-107 (2012).

30. Shen, B. et al. A directional switch of integrin signalling and a new antithrombotic strategy. Nature 503, 131-135 (2013).

31. Schror, K. \& Weber, A. A. Comparative pharmacology of GP IIb/IIIa antagonists. J. Thromb. Thrombolysis 15, 71-80 (2003).

32. Magallon, J. et al. Humanized mouse model of thrombosis is predictive of the clinical efficacy of antiplatelet agents. Circulation 123, 319-326 (2011)

33. Emsley, P., Lohkamp, B., Scott, W. G. \& Cowtan, K. Features and development of Coot. Acta Crystallogr. D Biol. Crystallogr. 66, 486-501 (2010).

34. Adams, P. D. et al. PHENIX: a comprehensive Python-based system for macromolecular structure solution. Acta Crystallogr. D Biol. Crystallogr. 66, 213-221 (2010)

35. Wallentin, L. et al. Ticagrelor versus clopidogrel in patients with acute coronary syndromes. N. Engl. J. Med. 361, 1045-1057 (2009).

36. Morrow, D. A. et al. Vorapaxar in the secondary prevention of atherothrombotic events. N. Engl. J. Med. 366, 1404-1413 (2012).

37. Miller, M. W. et al. Small-molecule inhibitors of integrin alpha2betal that prevent pathological thrombus formation via an allosteric mechanism. Proc. Natl Acad. Sci. USA 106, 719-724 (2009).

38. Ungerer, M. et al. Novel antiplatelet drug revacept (Dimeric Glycoprotein VIFc) specifically and efficiently inhibited collagen-induced platelet aggregation without affecting general hemostasis in humans. Circulation 123, 1891-1899 (2011).

39. Hohmann, J. D. et al. Delayed targeting of CD39 to activated platelet GPIIb/ IIIa via a single-chain antibody: breaking the link between antithrombotic potency and bleeding? Blood 121, 3067-3075 (2013).

40. Zheng, Z. et al. Discovery and antiplatelet activity of a selective PI3Kbeta inhibitor (MIPS-9922). Eur. J. Med. Chem. 122, 339-351 (2016).

41. Wang, Y. et al. Leukocyte integrin Mac-1 regulates thrombosis via interaction with platelet GPIbalpha. Nat. Commun. 8, 15559 (2017).

42. Zhu, J. et al. Structure-guided design of a high-affinity platelet integrin alphaIIbbeta3 receptor antagonist that disrupts $\mathrm{Mg}(2)(+)$ binding to the MIDAS. Sci. Transl. Med. 4, 125 ra132 (2012).

43. Li, J. et al. RUC-4: a novel alphaIIbbeta3 antagonist for prehospital therapy of myocardial infarction. Arterioscler. Thromb. Vasc. Biol. 34, 2321-2329 (2014).

44. Andre, P. et al. CD40L stabilizes arterial thrombi by a beta3 integrin-dependent mechanism. Nat. Med. 8, 247-252 (2002)

45. Wolf, D. et al. Binding of CD40L to Mac-1's I-domain involves the EQLKKSKTL motif and mediates leukocyte recruitment and atherosclerosisbut does not affect immunity and thrombosis in mice. Circ. Res. 109, 1269-1279 (2011)

46. Jenkins, A. L. et al. Tyrosine phosphorylation of the beta3 cytoplasmic domain mediates integrin-cytoskeletal interactions. J. Biol. Chem. 273, 13878-13885 (1998).

47. Litvinov, R. I., Farrell, D. H., Weisel, J. W. \& Bennett, J. S. The platelet integrin alphaIIbbeta3 differentially interacts with fibrin versus fibrinogen. J. Biol. Chem. 291, 7858-7867 (2016)

48. Mousa, S. A., Khurana, S. \& Forsythe, M. S. Comparative in vitro efficacy of different platelet glycoprotein IIb/IIIa antagonists on platelet-mediated clot strength induced by tissue factor with use of thromboelastography: differentiation among glycoprotein IIb/IIIa antagonists. Arterioscler. Thromb. Vasc. Biol. 20, 1162-1167 (2000).

49. Podolnikova, N. P. et al. The interaction of integrin alphaIIbbeta3 with fibrin occurs through multiple binding sites in the alphaIIb beta-propeller domain. J. Biol. Chem. 289, 2371-2383 (2014). 
50. Savage, B. \& Ruggeri, Z. M. Selective recognition of adhesive sites in surfacebound fibrinogen by glycoprotein IIb-IIIa on nonactivated platelets. J. Biol. Chem. 266, 11227-11233 (1991).

51. Hamaguchi, M., Bunce, L. A., Sporn, L. A. \& Francis, C. W. Spreading of platelets on fibrin is mediated by the amino terminus of the beta chain including peptide beta 15-42. Blood 81, 2348-2356 (1993).

52. Tam, S. H., Sassoli, P. M., Jordan, R. E. \& Nakada, M. T. Abciximab (ReoPro, chimeric 7E3 Fab) demonstrates equivalent affinity and functional blockade of glycoprotein IIb/IIIa and alpha(v)beta3 integrins. Circulation 98, 1085-1091 (1998).

53. Topol, E. J. et al. Multi-year follow-up of abciximab therapy in three randomized, placebo-controlled trials of percutaneous coronary revascularization. Am. J. Med. 113, 1-6 (2002).

54. Admiral, I. Three-year duration of benefit from abciximab in patients receiving stents for acute myocardial infarction in the randomized doubleblind ADMIRAL study. Eur. Heart J. 26, 2520-2523 (2005).

55. Sheldrake, H. M. \& Patterson, L. H. Function and antagonism of beta 3 integrins in the development of cancer therapy. Curr. Cancer Drug Targets $\mathbf{9}$, 519-540 (2009).

56. Trikha, M. et al. Multiple roles for platelet GPIIb/IIIa and alphavbeta3 integrins in tumor growth, angiogenesis, and metastasis. Cancer Res. 62, 2824-2833 (2002).

57. Gomes, N. et al. Breast adenocarcinoma cell adhesion to the vascular subendothelium in whole blood and under flow conditions: effects of alphavbeta3 and alphaIIbbeta3 antagonists. Clin. Exp. Metastasis 21, 553-561 (2004).

58. Engebraaten, O., Trikha, M., Juell, S., Garman-Vik, S. \& Fodstad, O. Inhibition of in vivo tumour growth by the blocking of host alpha(v)beta3 and alphaII(b) beta3 integrins. Anticancer Res. 29, 131-137 (2009).

59. Liu, Y. et al. The roles of platelet GPIIb/IIIa and alphavbeta3 integrins during HeLa cells adhesion, migration, and invasion to monolayer endothelium under static and dynamic shear flow. J. Biomed. Biotechnol. 2009, 829243 (2009).

60. Honda, S. et al. Topography of ligand-induced binding sites, including a novel cation-sensitive epitope (AP5) at the amino terminus, of the human integrin beta 3 subunit. J. Biol. Chem. 270, 11947-11954 (1995).

61. Tokuhira, M. et al. A novel regulatory epitope defined by a murine monoclonal antibody to the platelet GPIIb-IIIa complex (alpha IIb beta 3 integrin). Thromb. Haemost. 76, 1038-1046 (1996).

62. Mukai, T. et al. Reassignment of a rare sense codon to a non-canonical amino acid in Escherichia coli. Nucleic Acids Res. 43, 8111-8122 (2015).

63. Silverman, A. P., Kariolis, M. S. \& Cochran, J. R. Cystine-knot peptides engineered with specificities for alpha(IIb)beta(3) or alpha(IIb)beta(3) and alpha(v)beta(3) integrins are potent inhibitors of platelet aggregation. J. Mol. Recognit. 24, 127-135 (2011).

64. Otwinowski, Z. \& Minor, W. Processing of X-ray Diffraction Data Collected in Oscillation Mode, Vol. 276 (Academic Press, 1997).

65. Fuentes, R. E. et al. A chimeric platelet-targeted urokinase prodrug selectively blocks new thrombus formation. J. Clin. Invest. 126, 483-494 (2016).

66. Hu, Z. \& Yang, Y. G. Full reconstitution of human platelets in humanized mice after macrophage depletion. Blood 120, 1713-1716 (2012).

67. Hayes, V. et al. Endothelial antigen assembly leads to thrombotic complications in heparin-induced thrombocytopenia. J. Clin. Invest. 127, 1090-1098 (2017).

68. Ray, G. B., Blair, H. A. \& Thomas, C. I. The spectrophotometric determination of certain blood pigments. J. Biol. Chem. 98, 63-83 (1932).

69. La Morte, W. W. Sample size calculations in research. https://www.uml.edu.

\section{Acknowledgements}

We thank Drs. Donald W. Landry, Shi-Xian Deng, and Alison Rinderspacher (Columbia University, NY, NY) for synthesis and chemical analysis of M-tirofiban, and Dr. Jennifer
Cochran (Stanford University, CA) for providing aIIb $\beta 3$-K562. We also thank Drs. Mark Ginsberg (UC San Diego, CA), Thomas J Kunicki (Scripps Research Institute, CA), and Makoto Handa (Keio University, Tokyo, Japan) for providing mAbs LIBS-1, AP5, and PT-25-2, respectively. B-95 $\Delta$ A cells and pCDF5-Har plasmid were kindly provided by Dr. Kensaku Sakamoto (RIKEN, Yokohama, Japan). This work was supported by NIH grants DK088327, DK48549, and HL141366 (to M.A.A.), DK101628 (to J.V.A.), and R01HL142122 and P01HL040387 (to M.P.) from the National Institutes of Diabetes, Digestive and Kidney diseases (NIDDK) and Heart, Lung and Blood (NHLBI) of the National Institutes of Health, a grant from the RICBAC Foundation (to M.A.A.) and grants from National Core Facility for Biopharmaceuticals, Ministry of Science and Technology, Taiwan (S.-W.L. and I.-S.Y.). A BioRxiv preprint version was first posted Dec 31, 2018

\section{Author contributions}

M.A.A. conceived and oversaw all experiments. B.D.A. and M.A.A. performed the aggregation and clot retraction assays. J.L.A. designed and performed the ligand and antibody binding studies. J.V.A. collected the diffraction data and refined the structures. J.V.A., J.X.P., and M.A.A. performed model building and structure analysis. S.-W.L. and I.-S.Y. generated the $v W F^{R H /+}$ NSG mice. V.H., H.S.A., and M.P. performed the mouse studies. All authors interpreted data. M.A.A. had the primary responsibility for writing the manuscript.

\section{Competing interests}

Massachusetts General Hospital has submitted patent applications on the compounds described in this manuscript with M.A.A. named as inventor. The other authors declare no competing interests.

\section{Additional information}

Supplementary information is available for this paper at https://doi.org/10.1038/s41467019-13928-2.

Correspondence and requests for materials should be addressed to M.A.A.

Peer review information Nature Communications thanks Heyu $\mathrm{Ni}$ and the other, anonymous, reviewer(s) for their contribution to the peer review of this work.

Reprints and permission information is available at http://www.nature.com/reprints

Publisher's note Springer Nature remains neutral with regard to jurisdictional claims in published maps and institutional affiliations.

Open Access This article is licensed under a Creative Commons Attribution 4.0 International License, which permits use, sharing, adaptation, distribution and reproduction in any medium or format, as long as you give appropriate credit to the original author(s) and the source, provide a link to the Creative Commons license, and indicate if changes were made. The images or other third party material in this article are included in the article's Creative Commons license, unless indicated otherwise in a credit line to the material. If material is not included in the article's Creative Commons license and your intended use is not permitted by statutory regulation or exceeds the permitted use, you will need to obtain permission directly from the copyright holder. To view a copy of this license, visit http://creativecommons.org/ licenses/by/4.0/

(C) The Author(s) 2020 